\title{
Model-based decision analysis applied to petroleum field development and management
}

Denis José Schiozer*, Antonio Alberto de Souza dos Santos, Susana Margarida de Graça Santos, and João Carlos von Hohendorff Filho

University of Campinas, PO Box 6052, 13083-970 Campinas, SP, Brazil

Received: 20 September 2018 / Accepted: 20 March 2019

\begin{abstract}
This work describes a new methodology for integrated decision analysis in the development and management of petroleum fields considering reservoir simulation, risk analysis, history matching, uncertainty reduction, representative models, and production strategy selection under uncertainty. Based on the concept of closed-loop reservoir management, we establish 12 steps to assist engineers in model updating and production optimization under uncertainty. The methodology is applied to UNISIM-I-D, a benchmark case based on the Namorado field in the Campos Basin, Brazil. The results show that the method is suitable for use in practical applications of complex reservoirs in different field stages (development and management). First, uncertainty is characterized in detail and then scenarios are generated using an efficient sampling technique, which reduces the number of evaluations and is suitable for use with numerical reservoir simulation. We then perform multi-objective history-matching procedures, integrating static data (geostatistical realizations generated using reservoir information) and dynamic data (well production and pressure) to reduce uncertainty and thus provide a set of matched models for production forecasts. We select a small set of Representative Models (RMs) for decision risk analysis, integrating reservoir, economic and other uncertainties to base decisions on risk-return techniques. We optimize the production strategies for (1) each individual RM to obtain different specialized solutions for field development and (2) all RMs simultaneously in a probabilistic procedure to obtain a robust strategy. While the second approach ensures the best performance under uncertainty, the first provides valuable insights for the expected value of information and flexibility analyses. Finally, we integrate reservoir and production systems to ensure realistic production forecasts. This methodology uses reservoir simulations, not proxy models, to reliably predict field performance. The proposed methodology is efficient, easy-to-use and compatible with real-time operations, even in complex cases where the computational time is restrictive.
\end{abstract}

\section{Nomenclature}

AC Abandonment Costs

B Benchmark return

BHP Bottom-Hole Pressure

CAPEX Investments in equipment and facilities

CLRM Closed-Loop Reservoir Management

CLFDM Closed-Loop Field Development and Management

E Expectation operator

Ei Specialized production strategy optimized for RMi

EMR Robust production strategy

EMV Expected Monetary Value

$\begin{array}{ll}\text { EVoF } & \text { Expected Value of Flexibility } \\ \text { EVoI } & \text { Expected Value of Information } \\ G_{p} & \text { Cumulative gas production } \\ \text { NCF } & \text { Net Cash Flow } \\ N_{p} & \text { Cumulative oil production } \\ \text { NPV } & \text { Net Present Value } \\ \text { NQDS } & \text { Normalized Quadratic Deviation with Signal } \\ \text { OPEX } & \text { Operational Expenditure } \\ \text { ORF } & \text { Oil Recovery Factor } \\ \mathrm{Q}_{\mathrm{g}} & \text { Gas rate } \\ \mathrm{Q}_{\mathrm{o}} & \text { Oil rate } \\ \mathrm{Q}_{\mathrm{w}} & \text { Water rate } \\ \mathrm{Q}_{\mathrm{wi}} & \text { Water injection rate } \\ \mathrm{R} & \text { Gross revenue } \\ \mathrm{RM} & \text { Representative Model } \\ \mathrm{S}_{\mathrm{B}-} & \text { Lower semi-deviation from B } \\ \mathrm{S}_{\mathrm{B}+} & \text { Upper semi-deviation from B }\end{array}$

\footnotetext{
* Corresponding author: denis@unicamp.br
} 


$\begin{array}{ll}\mathrm{S}_{\mathrm{B}-}^{2} & \text { Lower semi-variance from B } \\ \mathrm{S}_{\mathrm{B}+}^{2} & \text { Upper semi-variance from B } \\ \mathrm{Roy} & \text { Amount paid in royalties } \\ \mathrm{ST} & \text { Amount paid in social taxes } \\ \mathrm{T} & \text { Corporate tax rate } \\ \mathrm{W}_{\mathrm{i}} & \text { Cumulative water injection } \\ \mathrm{W}_{\mathrm{p}} & \text { Cumulative water production } \\ \varepsilon(\mathrm{NPV}) & \text { Economic value of the production strategy } \\ & \text { adjusted to the decision maker's attitude } \\ \tau_{\mathrm{dr}} & \text { Tolerance level to downside risk } \\ \tau_{\mathrm{up}} & \text { Tolerance level to upside potential }\end{array}$

\section{Subscript}

wi With information

woi Without information

\section{Introduction}

Field development and management decisions involve risks due to several uncertainties, mainly (1) reservoir, associated with recoverable reserves and flow characteristics, (2) operational, related to production system availability, and (3) economic, such as oil price, capital expenditures, and operational expenditures. These uncertainties typically coexist because data is usually acquired indirectly and sparsely, and because developing a petroleum field is a longterm, capital-intensive project. Their combined effects must be assessed to estimate the risks involved in decisions.

Today, due to the challenges of new oil and gas discoveries, decision makers recognize the shortcomings of simplistic uncertainty assessments and the importance of integrated model-based decision analysis. In particular, current research focuses on improving the decision-making process in field development and management, making use of new information that arrives as new development wells are drilled and production begins. In this context, the Closed-Loop Reservoir Management (CLRM) was proposed (Chen et al., 2009; Jansen et al., 2005, 2009; Nævdal et al., 2006; Wang et al., 2009), which consists of a continuous update of the geological model accompanied by a continuous optimization of well-control for existing and future wells. Based on this concept, the Closed-Loop Field Development (CLFD) was generalized (Shirangi and Durlofsky, 2015) to include the continuous optimization of decision variables related to the production strategy configuration (e.g., type and position of future wells). This study is based on the CLFD concept.

However, many factors make this a complex, timeconsuming process to model, namely (1) the coexistence of multiple endogenous and exogenous uncertainties, (2) the large search spaces, and that (3) flow simulation is time-consuming in itself. In addition, this is a multidisciplinary problem, integrating reservoir engineering, production engineering, economic evaluation, and statistical analyses. Thus, simplifications are often required in analyses that perform a high number of evaluations, such as uncertainty quantification, optimization procedures, and decision risk analysis. However, these simplifications may yield inaccurate results and so must be selected carefully.

Proxy models, which are used to bypass the flow simulator, are a common simplification in uncertainty quantification, history matching, and probabilistic forecasting (Douarche et al., 2014; Feraille, 2013; Feraille and Marrel, 2012; Imrie and Macrae, 2016; Osterloh, 2008; Panjalizadeh et al., 2014; Scheidt et al., 2007; Touzani and Busby, 2014). However, multiple factors affect prediction accuracy of the proxy, which is not physics-based: (1) the high nonlinearity between input variables (reservoir, operational, and economic uncertainties) and output variables (production, injection, and economic forecasts) complicates proxy modeling, and (2) assumptions and approximations when modeling the proxy may introduce non-negligible errors (Trehan et al., 2017).

Lower-fidelity models, another class of approximations, have also been applied in history matching (Lodoen and Omre, 2008; Subbey et al., 2004) and production strategy optimization (Aliyev and Durlofsky, 2015; Wilson and Durlofsky, 2013). Lower-fidelity models entail many simplifications to increase computational efficiency while respecting the physical processes governing the reservoir. In this approach, high-fidelity models are upscaled through numerical homogenization procedures, prior to flow simulation. This simplification is attractive because upscaling is relatively straightforward to implement (Trehan et al., 2017). However, its use is not straightforward because upscaling errors arise from neglecting subgrid heterogeneity effects (Durlofsky, 1997, 1998; Preux, 2016; Zabalza-Mezghani et al., 2004).

Computational efficiency can also be achieved through efficient sampling. The Monte Carlo method is often used in the petroleum industry. However, as the sampling is purely random, a very high number of samples is necessary to ensure reliable results (Mishra, 1998), frequently at unfeasible levels (Risso et al., 2011). This study uses a simplified statistical technique developed in a related work (Schiozer et al., 2017), the Discretized Latin Hypercube with Geostatistical realizations (DLHG). By incorporating the desirable features of random sampling and stratified sampling, the DLHG ensures minimum computational costs without requiring proxy models. We tested this technique in several examples, achieving a good balance of precision and computational time. This sampling technique was applied to uncertainty quantification (Schiozer et al., 2017), history matching (Maschio and Schiozer, 2016), and production strategy optimization (von Hohendorff Filho et al., 2016).

This study also increases the computational efficiency of the CLFD process by using representative models of the uncertain system. Techniques to select representative models were the focus of recent research (Jiang et al., 2016; Meira et al., 2016, 2017; Shirangi and Durlofsky, 2016). This work applies a method developed in related research (Meira et al., 2016, 2017) to reduce the number of scenarios for production strategy selection and optimization. The method combines a mathematical function that captures the representativeness of a set of models with a metaheuristic optimization algorithm, to ensure full representation of the 
variability of system inputs (uncertain attributes) and outputs (production and economic forecasts). Additional advantages include low computational cost and simplicity for day-to-day decision making because the method is software based. Production strategy optimization is computationally consuming because of the high number of evaluations required. This is particularly challenging for the Robust Optimization (van Essen et al., 2009; Yang et al., 2011; Yasari and Pishvaie, 2015), where multiple scenarios are evaluated simultaneously.

For the methodology to deliver reliable results, some conditions must be guaranteed:

- The performance of a high-fidelity model must be preserved using an accurate simulation model because of the complex integration between the production strategy and the system performance (production, injection, and economic forecasts) (Botechia et al., 2018a).

- The reservoir simulation model must honor all dynamic data and be fast enough to allow analyses of multiple scenarios.

- The statistical analysis must be carefully performed to ensure adequate uncertainty representation while avoiding a high number of evaluations (which is very time consuming).

- The procedure for production strategy selection must reflect the effects of both the uncertain models and the production strategy because both highly influence the performance of the project and, consequently, the risk evaluation.

- Production and economic evaluations must be integrated because both of them impact decisions.

This work presents a methodology that resulted from several case studies and was first outlined in Schiozer et al. (2015). The method comprises the key steps of decision analysis to ensure good decisions. We integrate key steps of reservoir characterization, data assimilation, and production optimization providing a core basis for specialized methodologies, as we demonstrate in the results section.

\section{Objectives}

Despite the growing concern for in-depth, model-based decision making, we observed that many solutions, presented in the literature and used in some companies, still entail many simplifications, which can be critical in complex cases. This is because industry professionals value fast, easy-to-apply techniques because of limited time and highly complex decisions.

The objective of this work is to improve the decisionmaking process in petroleum field development and management. We present a model-based methodology integrating reservoir simulation, risk analysis, history matching, uncertainty reduction, representative models, and production strategy selection under uncertainty.

This method aims to ensure good decisions while being practical for application in complex reservoirs and at different stages of the field lifetime, both before and after reservoir development. Specific objectives of this study include: (1) practical for day-to-day decisions and based on reliable production forecasts from numerical reservoir simulation, (2) probabilistic-based decision-making based on an adequate representation of uncertainty, and (3) quantitative and objective decision-making based on indicators and automated procedures.

The methodology was applied to UNISIM-I-D, a benchmark case based on the Namorado field in the Campos Basin, Brazil.

\section{Methodology}

The proposed method is based on the concept of ClosedLoop Field Development and Management, as an extension of the Closed-Loop Reservoir Management by Jansen et al. (2009) (Fig. 1). The main components of the process are divided into colors:

- Green: gathering of all data and uncertainties and model construction; multiple simulation models are used in the process so model fidelity (low, medium or high) is adapted to balance quality of the results and computational time.

- Blue: model-based, long-term decisions under uncertainties; the best alternative is implemented in the field (with operational noise due to delays, fails, etc.) generating measured dynamic data (production, pressure, 4D seismic, etc.).

- Red: data assimilation; all dynamic data must be within a tolerance range to select models that will be used in the blue part; data assimilation may directly change the simulation models or the high fidelity geologic models (big loop).

- Black: (1) implementation of long-term decisions (normally model-based) and short-term decisions (normally data-driven), (2) definition of study objective, and (3) selection of the type of study (past - data assimilation; or future - decision analysis). below:

The twelve steps of the methodology are described

\subsection{Green steps}

1. Reservoir characterization under uncertainties (to build models, develop scenarios, and estimate probabilities) (Correia et al., 2015, 2018a, 2018b; Mahjour et al., 2019). This crucial step requires a multidisciplinary approach to consider all possible uncertainties: reservoir, fluid, economic, and operational attributes.

2. Build and calibrate the simulation model: accurate risk quantification requires reliable responses; therefore, the simulation model must be calibrated to have a fast and yet robust response to avoid biased evaluations (Avansi et al., 2019). Decision makers define the degree of model precision according to the objective. We believe that a high-fidelity model should be preferred over low-fidelity or proxy models because 


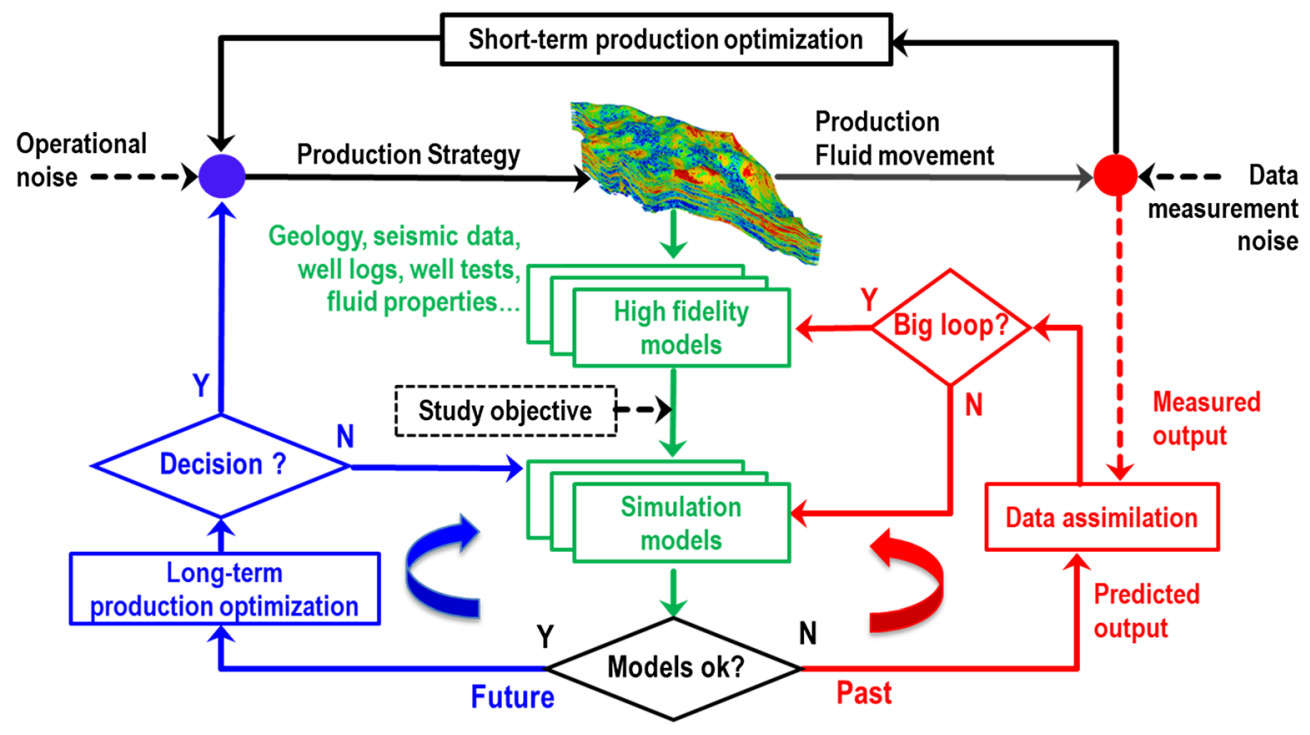

Fig. 1. Closed-loop field development and management (modified from Jansen et al., 2009).

of the high nonlinearity between the reservoir model and the production strategy performance. The calibration is normally done with a Base Case (in this work, called Base0).

\subsection{Red steps}

3. Verify inconsistencies in the Base Case and dynamic well data (fluid rates and BHP measurements) to be used in the data assimilation procedures. This step is often simplified or skipped but it is crucial as it can identify inconsistencies in the simulation model and the real data.

4. Generate scenarios considering reservoir uncertainties. In this work, a scenario is a particular combination of all possible uncertainties. Several sampling techniques are available in the literature, but we recommend the efficient DLHG (Schiozer et al., 2017).

5. Data assimilation: history match and reduce the number of scenarios with dynamic and seismic data. Several techniques are available (Avansi and Schiozer, 2015a; Bertolini et al., 2015; Costa et al., 2018; Davolio and Schiozer, 2018; Maschio and Schiozer, 2008, 2015, 2016; Oliveira et al., 2018) depending on the complexity of the case and the available data. From the accepted models, a Base Case is selected for the following steps (Base1). The usual recommendation is to use a model close to P50 in all indicators to optimize the initial production strategy, representing an intermediate case. A new Base Case must be selected only when Base0 fails to honor the dynamic data or is too optimistic or pessimistic.

\subsection{Blue steps}

6. Selection of a deterministic production strategy for the Base Case. As the production strategy selection strongly affects the risk quantification, an iterative technique is best to select the production strategy. The first production strategy is selected using an optimization procedure (Gaspar et al., 2014, 2016a; Ravagnani et al., 2011; von Hohendorff Filho et al., 2016).

7. Initial risk estimate of the first production strategy with all possible scenarios (from Step 5). This risk curve is often used in projects. Here, we propose additional analyses (Steps 8-12) to further improve decisions and reduce risk, showing that the final risk curve can be very different.

8. Selection of Representative Models (RMs) (Costa et al., 2008; Meira et al., 2016, 2017; Schiozer et al., 2004) based on multiple system inputs (probability distribution and range of uncertain attributes) and outputs (production, injection, and economic forecasts).

9. Selection of a specialized production strategy for each RM, as in Step 6, to provide different solutions for field development.

10. Production strategy selection under uncertainty including reservoir, economic, and other uncertainties. A Robust Optimization procedure (Silva et al., 2016) can be used, or a risk-return analysis (Santos et al., 2017a) to select the best strategy from the candidates obtained in Step 9. If the simulation runtime for the number of scenarios is unfeasible, the RMs can be used to represent them.

11. Identification of potential changes in the production strategy (obtained in Step 10) to manage uncertainty and improve the chance of success based on the value of information (Botechia et al., 2018b; Santos et al., $2017 \mathrm{~b}$ ) and value of flexibility analyses (Santos et al., 2018a; Silva et al., 2017), and integration with production facilities (von Hohendorff Filho and Schiozer, 2017, 2018). If the simulation runtime for the number of scenarios is unfeasible, the RMs can be used to represent them. 


\subsection{Black step}

12. The black step is dedicated to the decision analysis. Technical and economic indicators support long-term, model-based decisions as well as short-term, datadriven decisions. The objective guides the process: model quality, need for further data assimilation (history matching), objective function selection, etc.

The literature provides several methods for each specific step of the comprehensive 12 steps of this study. We referenced methods for specific steps that we have conducted in related works. The discussion section explores the focus of our current research to address existing challenges.

\section{Application}

The 12-step methodology was applied to a benchmark case study based on the Namorado field in the Campos Basin, Brazil. A synthetic reservoir, UNISIM-I-R (Avansi and Schiozer, 2015b), was built to provide a reference model that represents the true reservoir. The uncertain simulation model UNISIM-I-D (Gaspar et al., 2015) is in the initial stages of field development and has four years of production data for four production wells (NA1A, NA2, NA3D, RJS19). The reservoir model is discretized into a corner point grid with $81 \times 58 \times 20$ cells measuring $100 \times$ $100 \times 8 \mathrm{~m}$ with a total of 36739 active cells.

We reference results from related studies in the results section. Note that our focus is not to compare the efficacy of each method, but to demonstrate that the 12-step decision-structure allows the development of different approaches.

\section{Results}

\subsection{Step 1}

The uncertainties of the model include:

- Reservoir attributes: geostatistical realizations of facies, porosity, net-to-gross ratio, and permeability; structural model (BL), water relative permeability $\left(K_{\mathrm{rw}}\right)$, fluid properties in the East block (PVT), depth of Water-Oil Contact in the East block (WOC), Rock Compressibility (CPOR), and vertical permeability multiplier $\left(K_{\mathrm{z}}\right)$ (Tab. 1$)$.

- Economic attributes: oil price, operational expenditures, and capital expenditures (Tab. 2).

- Operational attributes: System Availability (SA) and Well Index Multiplier (dWI) (Tab. 3).

Details of the simulation model, economic model, and uncertainties can be found in Avansi and Schiozer (2015b) and in Gaspar et al. (2015), while open source files can be accessed at http://www.unisim.cepetro.unicamp.br/ unisim-i.

\subsection{Steps 2 and 3}

Step 2 guarantees that the simulation model adequately represents the reservoir and is fast enough to be included in a methodology that demands thousands of simulation runs. In our case, the simulation runtime was around 7 min running in parallel while using four processors in a cluster. Although our methodology is applicable to cases with very high runtimes (hours), simplifications may be necessary depending on the time available and scope of the project.

Step 3 ensures compatibility of the initial response of the Base Case (Base0) (material balance, pressure, and initial production) with the existing data. Note that the Base0 case corresponds to the most likely value of each uncertain attribute.

\subsection{Step 4}

In Step 4, scenarios were generated to start the probabilistic process using the DLHG (Schiozer et al., 2017), which applies the efficient Latin Hypercube Sampling (LHS) and integrates all types of uncertainties in the sampling step, i.e., continuous attributes are discretized, and then combined with discrete attributes and geostatistical realizations. In LHS, the range of each variable $\left(x_{j}\right)$ is divided into $n$ disjoint intervals of equal probability, then one value is selected at random from each interval. The $n$ values obtained for $x_{1}$ are randomly paired, not replaced, with the $n$ values obtained for $x_{2}$. This process is continued until a set of $n n X$-tuples is formed (Helton and Davis, 2003).

Each attribute is treated according to (1) sampling number, (2) number of discrete levels, and (3) probability of each discrete level. The sampling number, which is equal to the number of flow simulation runs, is set at the beginning of the process based on (1) simulation runtime, (2) importance of the study (i.e., the required precision), and (3) available work time (Schiozer et al., 2017). Note that all sampled scenarios are simulated using the flow simulator while no proxy models are used for production forecasts.

Santos et al. (2018b) showed that independence between the precision of the DLHG and the number of samples is achieved with a few samples (from 50 samples for UNISIM-I-D). Due to the short simulation runtime and the available computational resources, we used more samples to create smoother risk curves. Figure 2 shows risk curves for sampling numbers 500 and 100. It is possible to notice that the Base Case is no longer close to P50 in the risk curve.

\subsection{Step 5}

In Step 5, we applied a filtering technique to select the subset of scenarios (from the full set of sampled scenarios) that matched the four years of production data. We used the Normalized Quadratic Deviation with Signal (NQDS) (Avansi and Schiozer, 2015a; Bertolini et al., 2015) as the matching indicator, which is normalized for each well and each objective function $\left(Q_{\mathrm{o}}, Q_{\mathrm{w}}, Q_{\mathrm{g}}\right.$, and BHP). We considered NQDS values between -1 and +1 an acceptable misfit. 
Table 1. Reservoir uncertainties for the simulation model (Avansi and Schiozer, 2015b). Level zero of each attribute is the base (most likely).

\begin{tabular}{|c|c|c|}
\hline Attribute & Uncertainty type & Levels (Probability) \\
\hline Image & Discrete (realization) & $\begin{array}{l}500 \text { geostatistical realizations of porosity, permeability, } \\
\text { and net-to-gross ratio (equiprobable) }\end{array}$ \\
\hline $\mathrm{BL}$ & Discrete (map) & Present (0.7); absent (0.3) \\
\hline$K_{\mathrm{rw}}$ & Discrete (curve) & krw0 (0.2); krw1 (0.2); krw2 (0.2); krw3 (0.2); krw4 (0.2) \\
\hline PVT & Discrete (table) & PVT0 (0.34); PVT1 (0.33); PVT2 (0.33) \\
\hline WOC & Continuous discretized (scalar) & woc0 (0.111); woc1 (0.2222); woc2 (0.334); woc3 (0.222); woc4 (0.111) \\
\hline CPOR & Continuous discretized (scalar) & cpor0 $(0.2)$; cpor1 $(0.6)$; cpor2 $(0.2)$ \\
\hline$K_{\mathrm{z}}$ & Continuous discretized (scalar) & kz0 (0.4); kz1 (0.1); kz2 (0.1); kz3 (0.2); kz4 (0.2) \\
\hline
\end{tabular}

Table 2. Economic parameters and uncertainties (Gaspar et al., 2015).

\begin{tabular}{|c|c|c|c|c|c|c|c|c|}
\hline \multirow[t]{2}{*}{ Description } & \multicolumn{4}{|c|}{ Field units } & \multicolumn{4}{|c|}{ SI units } \\
\hline & Units & Base & Optimistic & Pessimistic & Units & Base & Optimistic & Pessimistic \\
\hline Oil price & $\mathrm{USD} / \mathrm{bbl}$ & 50 & 70 & 40 & $\mathrm{USD} / \mathrm{m}^{3}$ & 314.5 & 440.3 & 251.6 \\
\hline Discount rate & $\%$ & 9 & 9 & 9 & $\%$ & 9 & 9 & 9 \\
\hline Royalties & $\%$ & 10 & 10 & 10 & $\%$ & 10 & 10 & 10 \\
\hline $\begin{array}{l}\text { Special taxes on } \\
\text { gross revenue }\end{array}$ & $\%$ & 9.25 & 9.25 & 9.25 & $\%$ & 9.25 & 9.25 & 9.25 \\
\hline Corporate taxes & $\%$ & 34 & 34 & 34 & $\%$ & 34 & 34 & 34 \\
\hline Cost of oil production & $\mathrm{USD} / \mathrm{bbl}$ & 10.0 & 13.0 & 8.0 & $\mathrm{USD} / \mathrm{m}^{3}$ & 62.9 & 81.8 & 52.4 \\
\hline Cost of water production & $\mathrm{USD} / \mathrm{bbl}$ & 1.0 & 1.3 & 0.8 & $\mathrm{USD} / \mathrm{m}^{3}$ & 6.3 & 8.2 & 5.3 \\
\hline Cost of water injection & $\mathrm{USD} / \mathrm{bbl}$ & 1.0 & 1.3 & 0.8 & $\mathrm{USD} / \mathrm{m}^{3}$ & 6.3 & 8.2 & 5.3 \\
\hline $\begin{array}{l}\text { Abandonment cost } \\
\text { (\% well investment) }\end{array}$ & $\%$ & 7.4 & 9.2 & 6.5 & $\%$ & 7.4 & 9.2 & 6.5 \\
\hline $\begin{array}{l}\text { Drilling and completion } \\
\text { of vertical well }\end{array}$ & USD Million & 61.2 & 76.5 & 54.0 & USD Million & 61.2 & 76.5 & 54.0 \\
\hline $\begin{array}{l}\text { Drilling and completion } \\
\text { of horizontal well }\end{array}$ & $\begin{array}{c}\text { USD } \\
\text { Thousand } / \mathrm{m}\end{array}$ & 21.7 & 27.3 & 19.0 & $\begin{array}{c}\text { USD } \\
\text { Thousand } / \mathrm{m}\end{array}$ & 27.3 & 19.0 & 21.7 \\
\hline Well-platform & USD Million & 13.3 & 16.7 & 11.7 & USD Million & 13.3 & 16.7 & 11.7 \\
\hline Probability & & 0.50 & 0.25 & 0.25 & & 0.50 & 0.25 & 0.25 \\
\hline
\end{tabular}

Table 3. Operational uncertainties (Gaspar et al., 2015).

\begin{tabular}{llccc}
\hline & & \multicolumn{3}{c}{ Levels } \\
\cline { 3 - 5 } Parameter & Uncertainty type & 0 (base) & 1 & 2 \\
\hline SA - Platform & Discrete (scalar) & 0.95 & 1.00 & 0.90 \\
SA - Group & Discrete (scalar) & 0.96 & 1.00 & 0.91 \\
SA - Producer & Discrete (scalar) & 0.96 & 1.00 & 0.91 \\
SA - Injector & Discrete (scalar) & 0.98 & 1.00 & 0.92 \\
dWI & Discrete (scalar) & 1.00 & 1.40 & 0.70 \\
Probability & & 0.33 & 0.34 & 0.33 \\
\hline
\end{tabular}

Figure 3 shows the 214 , out of the 500 initial scenarios, selected (with all objective functions within the tolerance range). Figure 4 shows water production curves for the four wells as an example.
As the Base Case, Base0, did not match the production data, we selected a new Base Case (Base1) as an intermediate case from the set of filtered models, using an initial production strategy (E0) (Fig. 5). Note that this initial strategy does not represent the final decision for field development and it is only used to select the Base1 case.

\subsection{Step 6}

The first important consideration is how to integrate production facilities with the field production forecast and modeling. Generally, when production facilities impose strong restrictions, integrated modeling is used in all of the blue steps. In other cases, and in this application, integrated modeling is used to establish approximate well boundary conditions in Step 6 and to confirm these conditions in Step 11. 

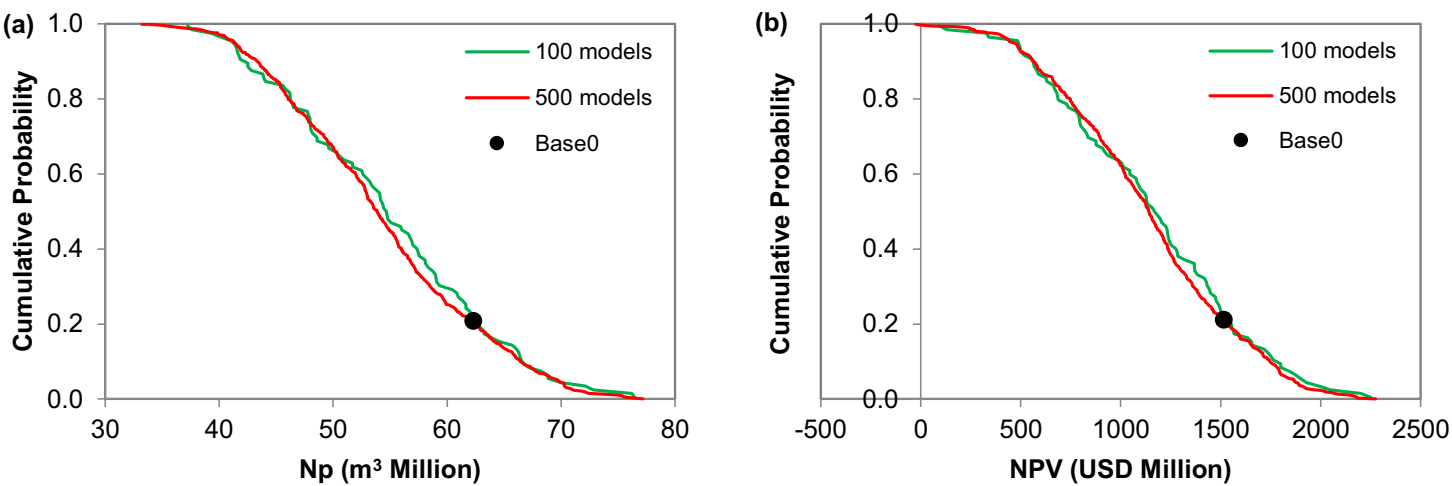

Fig. 2. a) Cumulative oil production $\left(N_{\mathrm{p}}\right)$ and b) Net Present Value (NPV) risk curves for production strategy E0 for 100 and 500 sampled scenarios, highlighting Base0.
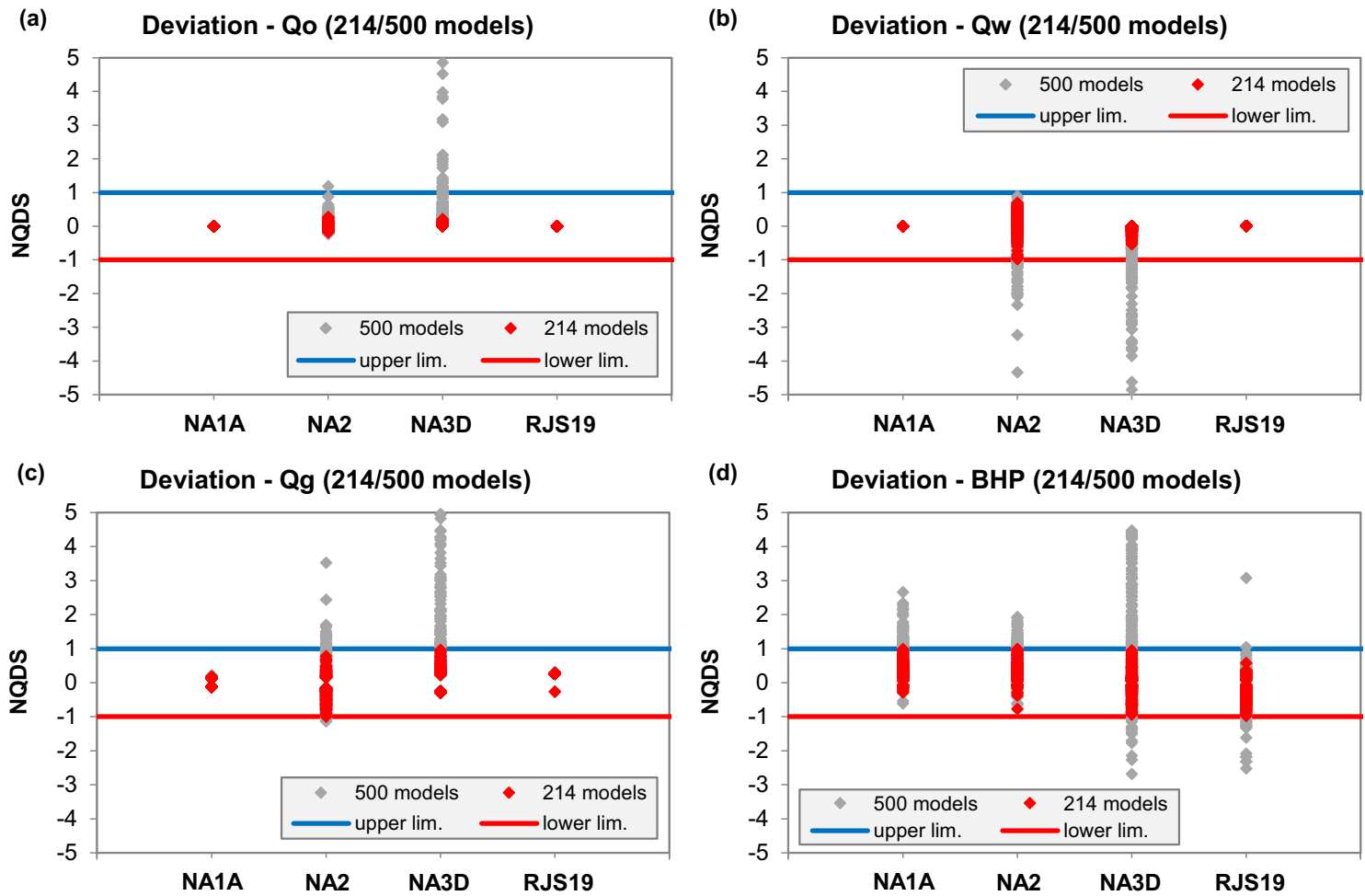

Fig. 3. NQDS for objective functions a) oil rate $\left(Q_{\mathrm{o}}\right)$, b) water rate $\left(Q_{\mathrm{w}}\right)$, c) gas rate $\left(Q_{\mathrm{g}}\right)$, and d) Bottom-Hole Pressure (BHP), for the four initial wells (NA1A, NA2, NA3D, RJS19) with production data: 500 initial scenarios (gray) and 214 filtered scenarios that match production data (red).

We optimized deterministically a production strategy for Base1, considering design (G1) and operation (G2) variables. The G1 variables were: number, type (vertical or horizontal), placement, and opening-schedule of wells, and platform capacity constraints (liquid, oil and water production, and water injection). The G2 variables were constraints of maximum water-cut, maximum liquid production for producers, and water injection for injectors.

The optimization procedure was divided into phases: (1) number and type of wells, and platform capacity,
(2) well placement and fine-tuning the platform capacity constraints, (3) well-opening schedule, (4) well operating and monitoring constraints, and (5) fine-tuning.

We performed phases 1,2 , and 4 on commercial software CMOST $\left(\mathrm{CMG}^{\odot}\right)$, which uses the optimizer method Designed Exploration Controlled Evolution (DECE) (Yang et al., 2007). We used the black-oil numerical reservoir simulator IMEX $\left(\mathrm{CMG}^{\odot}\right)$.

The objective function for optimization is the Net Present Value (NPV) (Fig. 6) and is calculated using the 

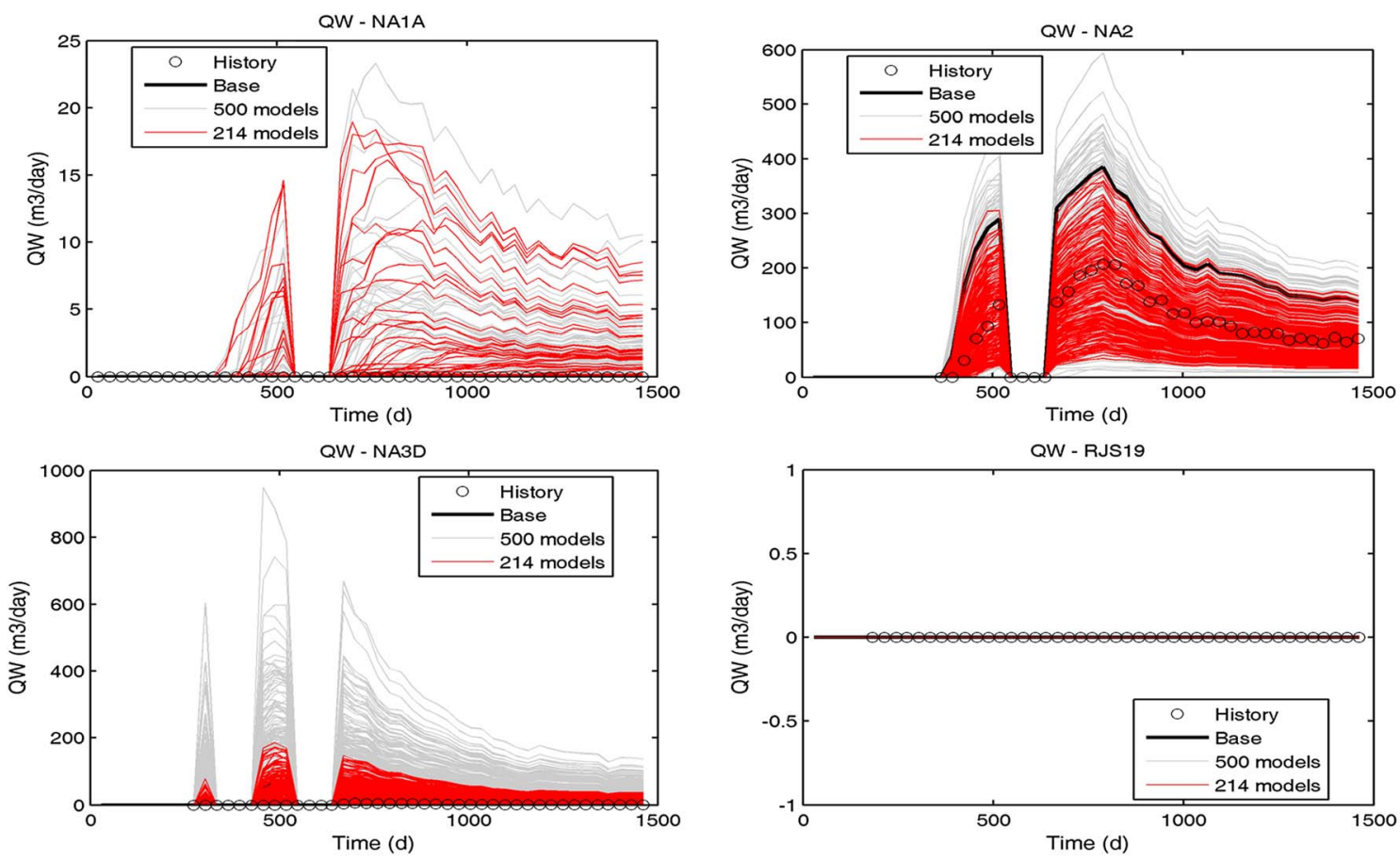

Fig. 4. Water production for the four initial wells (NA1A, NA2, NA3D, RJS19) with production data: 500 initial scenarios (gray) and 214 filtered scenarios that match production data (red).
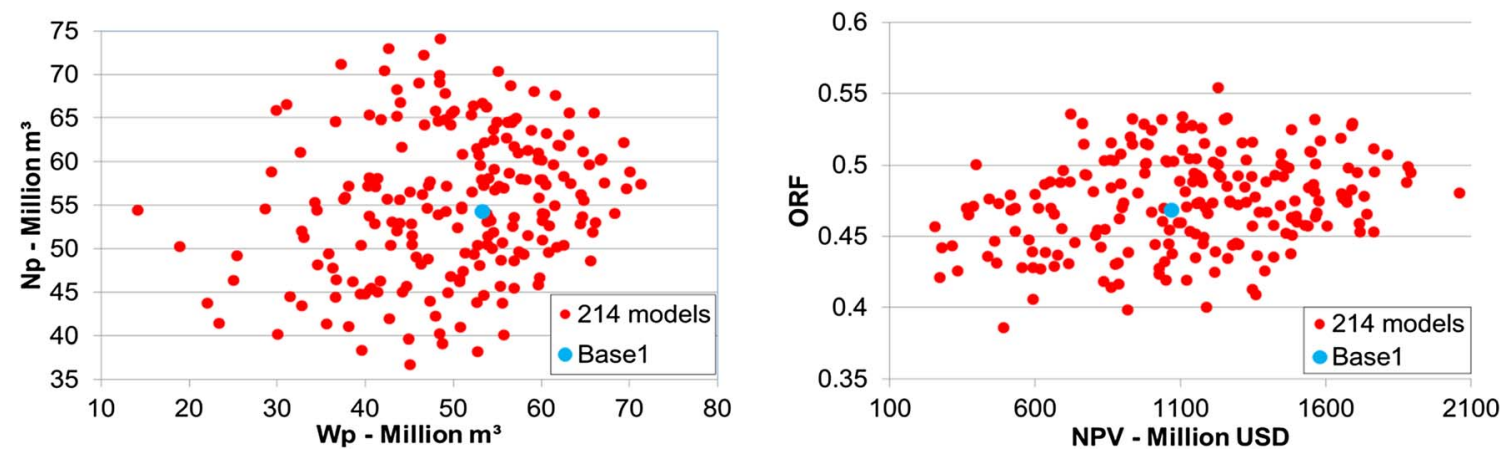

Fig. 5. Cross-plots for cumulative water production versus cumulative oil production $\left(W_{\mathrm{p}} \times N_{\mathrm{p}}\right)$, and net present value versus oil recovery factor $(\mathrm{NPV} \times \mathrm{ORF})$ for production strategy E0, for the 214 models (red circles), highlighting the intermediate case chosen as Base1 (blue circle).

most likely economic scenario (Tab. 3) and a simplified net cash flow formula based on the Brazilian Royalty \& Taxes fiscal regime (eq. (1)).

$$
\begin{aligned}
\mathrm{NCF}= & {[(R-\text { Roy }-\mathrm{ST}-\mathrm{OPEX}) \times(1-T)] } \\
& -\mathrm{CAPEX}-\mathrm{AC},
\end{aligned}
$$

where $\mathrm{NCF}$ is the net cash flow, $R$ is the gross revenue, Roy is the amount paid in royalties, ST is the amount paid in social taxes, OPEX is the operational expenditure, $T$ is the corporate tax rate, CAPEX is the investment in equipment and facilities, and $\mathrm{AC}$ are the abandonment costs.
The production strategy for Base1 is called E1 and consists of:

- Number and type of wells: 10 horizontal producers, two vertical producers (existing wells NA1A and NA3D), six horizontal water injectors, in a total of 18 conventional wells.

- Platform capacity constraints: $16275 \mathrm{~m}^{3}$ /day (liquid and oil production), $9068 \mathrm{~m}^{3}$ /day (water production), and $23328 \mathrm{~m}^{3} /$ day (water injection).

At the end of the prediction period (10 957 days), E1 recorded: NPV of USD 2236 million, $N_{\mathrm{p}}$ of 65 million $\mathrm{m}^{3}$, 

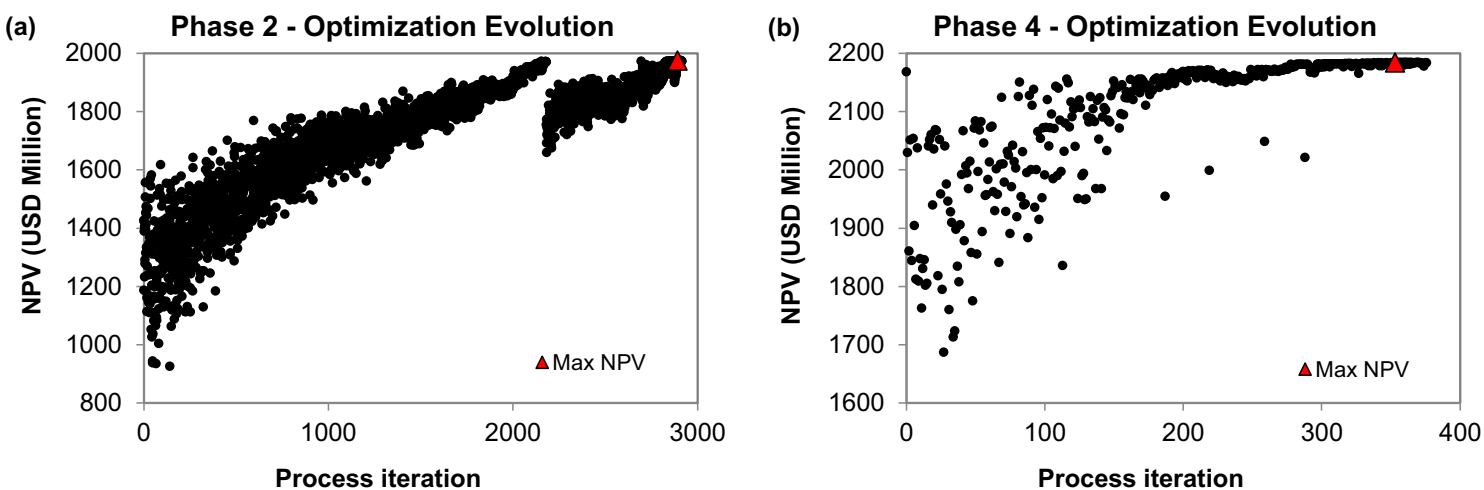

Fig. 6. Evolution of the NPV with the optimization procedure for a) phase 2 and b) phase 4 .
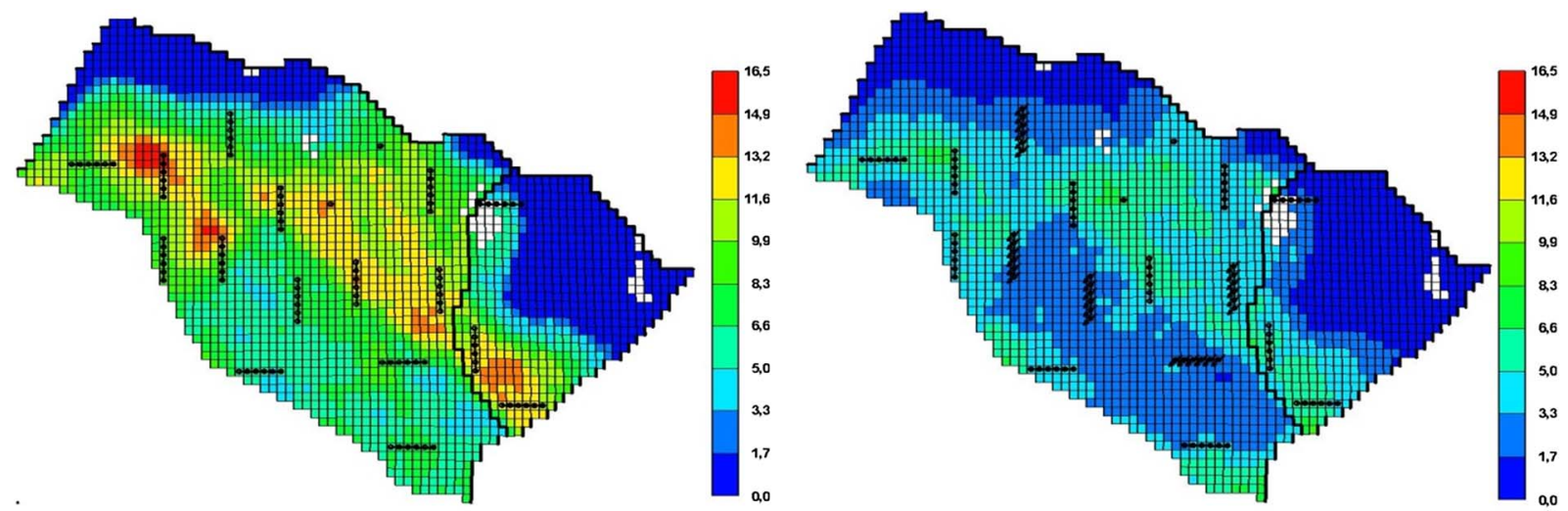

Fig. 7. Map of total oil per unit area at the beginning (left) and end (right) of the prediction period, including well placement for production strategy E1.

$W_{\mathrm{p}}$ of 50 million $\mathrm{m}^{3}, G_{\mathrm{p}}$ of 6892 million $\mathrm{m}^{3}, W_{\mathrm{i}}$ of 138 million $\mathrm{m}^{3}$, and Oil Recovery Factor (ORF) of $56 \%$. Figure 7 compares the map of total oil per unit area at the beginning and end of the prediction period, showing the well placement of E1.

\subsection{Step 7}

We conducted a first risk estimate using production strategy E1 and the 214 possible scenarios from Step 5 (Fig. 8). Risk curves are also referred to as descending or complementary cumulative distribution functions in the statistics literature, and we constructed them with the production forecasts of multiple scenarios from numerical reservoir simulation.

One interesting point to highlight here, which is normally neglected in many analyses, is the relationship between the uncertainties and the production strategy. Base1, the intermediate case for E0 (Fig. 5), became an optimistic case for E1 (Fig. 8). We observed this behavior in other cases. Once a strategy is optimized for a particular model, it becomes more optimistic considering the optimized output parameters (NPV for instance).

Note that these risk curves do not reflect the final risk assessment for this project, but provide input for Step 8 .

\subsection{Step 8}

We applied the proposal by Meira et al. (2016) to select nine RMs from the 214 matched models using multiple risk curves and cross-plots for four objective functions: NPV, $N_{\mathrm{p}}, W_{\mathrm{p}}$, and ORF (examples in Figs. 9 and 10). Geostatistical realizations are particularly difficult to handle, and from the set of 214 , we used only nine.

The proposal by Meira et al. (2016) ensures that the set of RMs represents both the probability distribution of the input variables (uncertain attributes), ensuring that not only attributes but also uncertain levels are represented, and the variability of the main output variables (production, injection, and economic forecasts). In addition, this method is applied using RMFinder software, improving ease-of-use.

As we already had production strategy E1, we took Base1 as one of the RMs (Base1 = RM1), saving time and computational costs.

\subsection{Step 9}

Because production strategy E1 was optimized specifically for Base1, we analyzed other possibilities for field development using the RMs obtained in Step 8. This follows the 

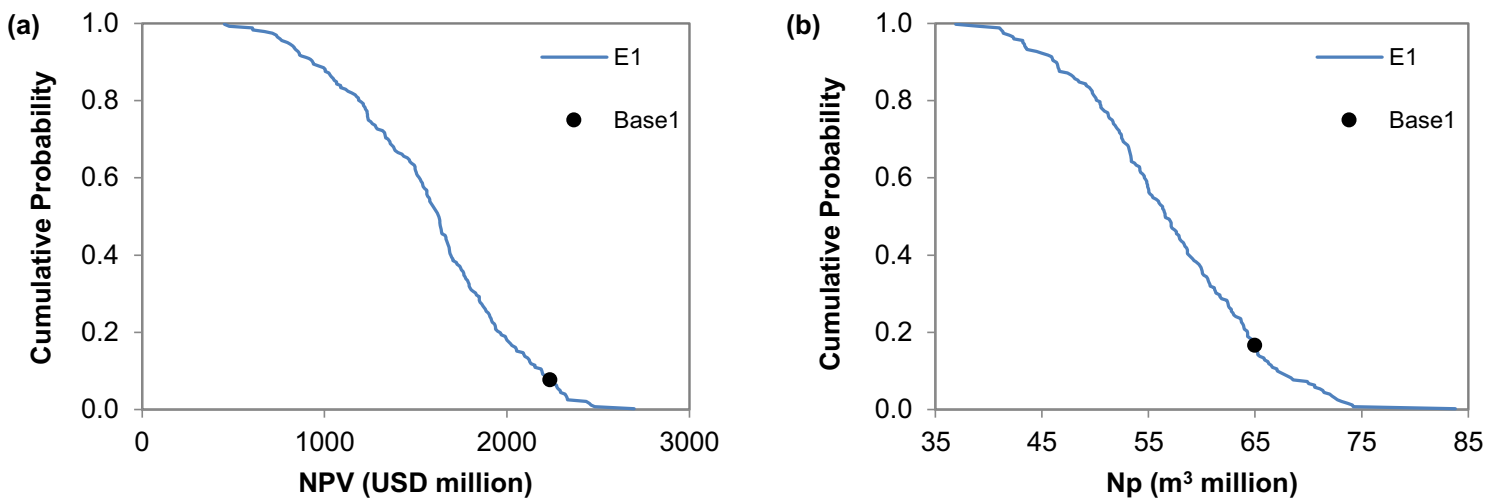

Fig. 8. NPV and $N_{\mathrm{p}}$ risk curves for production strategy E1, highlighting Base1 (circle).
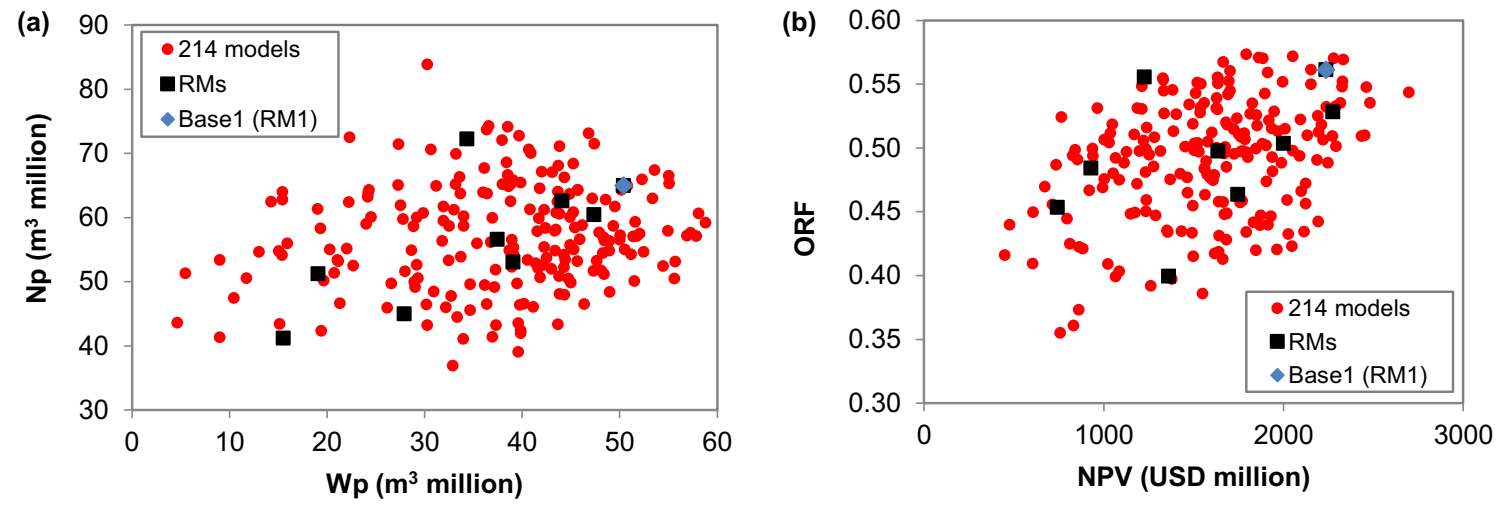

Fig. 9. Cross-plots for a) $W_{\mathrm{p}} \times N_{\mathrm{p}}$ and b) NPV $\times$ ORF, for production strategy E1, for the 214 models (red circles), highlighting Base1 (blue diamond) and nine RMs (black squares).
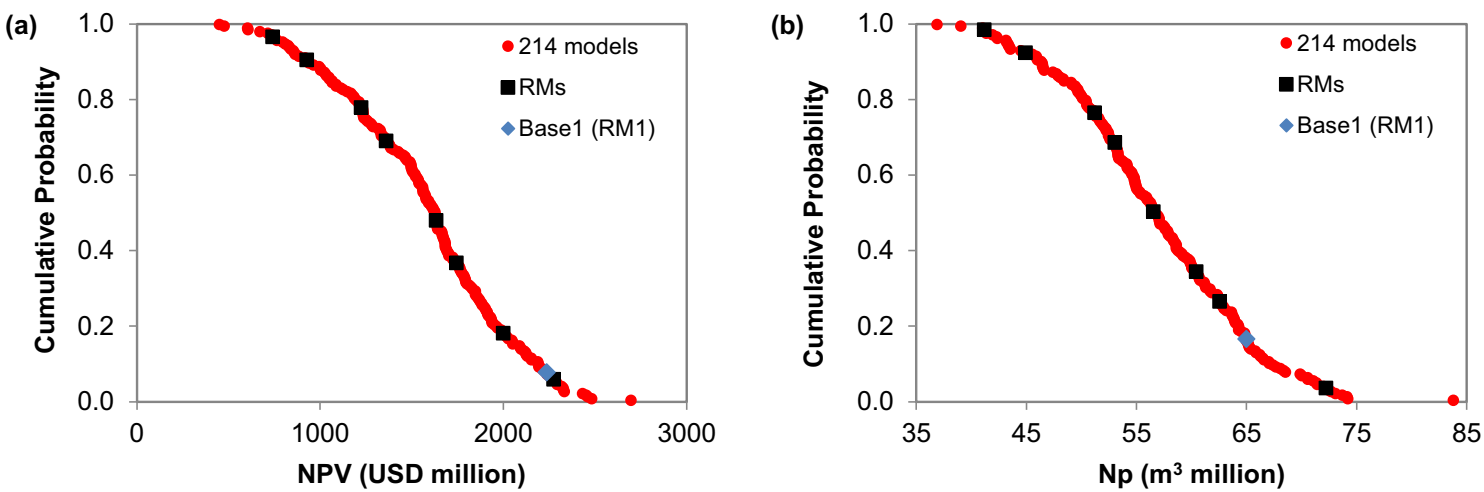

Fig. 10. a) NPV and b) $N_{\mathrm{p}}$ risk curves for production strategy E1, for the 214 models (red circles), highlighting Base1 (blue diamond) and nine RMs (black squares).

rationale that, if the set of $\mathrm{RMs}$ represents the uncertain system, their respective production strategies provide different field development possibilities, including number and placement of wells and platform processing capacities.

We repeated the optimization procedure (described in Step 6) for each RM, obtaining a set of specialized strategies: E2, E3, ..., E9 (Tab. 4), where Ei is the strategy optimized for RMi.

A key uncertainty affecting production strategy selection is the structural model (Fig. 11). The presence of hydrocarbons in the, still undrilled, East block is uncertain because the connectivity of the fault separating the 
Table 4. Characteristics of the nine production strategies (E1-E9). Prod.: number of producing wells; Inj.: number of water injection wells.

\begin{tabular}{|c|c|c|c|c|c|c|c|c|c|c|c|}
\hline \multirow{2}{*}{$\begin{array}{l}\text { Production } \\
\text { strategy }\end{array}$} & \multicolumn{3}{|c|}{ Wells in West block } & \multicolumn{3}{|c|}{ Wells in East block } & \multirow{2}{*}{$\begin{array}{l}\text { Total } \\
\text { wells }\end{array}$} & \multicolumn{4}{|c|}{ Platform $\left(1000 \mathrm{~m}^{3} /\right.$ day $)$} \\
\hline & Prod & Inj & Total & Prod & Inj & Total & & $Q_{1}$ & $Q_{\mathrm{o}}$ & $Q_{\mathrm{w}}$ & $Q_{\mathrm{wi}}$ \\
\hline E1 & 10 & 5 & 15 & 2 & 1 & 3 & 18 & 16.3 & 16.3 & 9.1 & 23.3 \\
\hline $\mathrm{E} 2$ & 8 & 5 & 13 & 2 & 1 & 3 & 16 & 16.3 & 16.3 & 11.2 & 22.8 \\
\hline E3 & 9 & 5 & 14 & 0 & 0 & 0 & 14 & 14.0 & 14.0 & 9.8 & 19.5 \\
\hline E4 & 9 & 5 & 14 & 2 & 1 & 3 & 17 & 18.2 & 18.2 & 11.5 & 25.5 \\
\hline E5 & 9 & 5 & 14 & 4 & 2 & 6 & 20 & 17.8 & 17.8 & 10.5 & 23.8 \\
\hline E6 & 9 & 6 & 15 & 0 & 0 & 0 & 15 & 14.3 & 14.3 & 7.3 & 20.6 \\
\hline E7 & 9 & 6 & 15 & 0 & 0 & 0 & 15 & 13.2 & 13.2 & 5.2 & 19.5 \\
\hline E8 & 10 & 5 & 15 & 4 & 2 & 6 & 21 & 21.7 & 21.7 & 14.6 & 29.8 \\
\hline E9 & 9 & 5 & 14 & 4 & 2 & 6 & 20 & 20.2 & 20.2 & 9.8 & 28.2 \\
\hline
\end{tabular}

West and the East blocks is unknown. Of the set of representative models, RM3, RM6, and RM7 do not have hydrocarbons in the East block and their respective production strategies (E3, E6, E7) are solutions for such scenarios.

\subsection{Step 10}

In Step 10, we select the production strategy that performs best under uncertainty, before considering further actions to manage this uncertainty (addressed in Step 11).

A production strategy is said to be robust when is insensitive to uncertainty and ensures good performance across multiple scenarios without requiring system modifications after production has started (de Neufville, 2004). However, note that the definition of robustness also depends on the company and can be associated with NPV or oil production. For a robust project related to NPV, lower investments can help avoid negative or lower NPV values for pessimistic scenarios. For a robust project related to oil production, higher investments can be made to increase rates in optimistic scenarios, for instance.

In Step 9, we obtained a set of specialized production strategies. One possible approach for Step 10 is to select the strategy that performs best under uncertainty. The Robust Optimization, an automated optimization problem formulated under uncertainty, is another approach that has become increasingly preferred by practitioners. Alternatively, a robust strategy can be obtained by manually refining the best specialized strategy, improving the performance under uncertainty (to be addressed in Step 11).

Following the concept of Robust Optimization, Silva et al. (2016) obtained the robust production strategy for UNISIM-I-D, called EMR, optimized for nine RMs and three economic scenarios, simultaneously. Thus, the key difference between the optimization procedure is that Step 6 simulates each strategy configuration for one reservoir scenario (resulting in one NPV), while Silva et al. (2016) simulate strategy configuration for many scenarios (resulting in one Expected Monetary Value [EMV]).
The robust EMR consists of:

- Number and type of wells: 15 producers and nine water injectors.

- Platform capacity constraints: $20150 \mathrm{~m}^{3}$ /day (liquid and oil production), $13950 \mathrm{~m}^{3}$ /day (water production), and $29295 \mathrm{~m}^{3} /$ day (water injection).

The literature provides several techniques for risk-return analyses to select one of a set of alternatives. Santos et al. (2017a) followed on from the classic mean-variance model and proposed a mean-semivariance framework based on the premise that variance reflects only the overall uncertainty in returns, and not necessarily the risk of a project. The risk (referred to here as downside risk) is the chance of failure to achieve a targeted or benchmark return (B). Thus, variability above this target is not perceived as risk, but as potentially exploitable optimistic scenarios (referred to here as upside potential) (Fig. 12).

Santos et al. (2017a) combined the expected monetary value, downside risk, and upside potential (eq. (2)) to determine the economic value of a production strategy adjusted to the decision maker's attitude, $\varepsilon(\mathrm{NPV})$, while maintaining the same units and dimension as the NPV:

$$
\varepsilon(\mathrm{NPV})=\mathrm{EMV}-\frac{\mathrm{S}_{\mathrm{B}-}^{2}}{\tau_{\mathrm{dr}}}+\frac{\mathrm{S}_{\mathrm{B}+}^{2}}{\tau_{\mathrm{up}}},
$$

where $\varepsilon(\mathrm{NPV})$ is the economic value of the production strategy adjusted to the decision maker's attitude (in USD); EMV is the expected monetary value, given by the sum of the NPV of each scenario weighted by its probability (in USD); $\mathrm{S}_{\mathrm{B}-}^{2}$ and $\mathrm{S}_{\mathrm{B}-}^{2}$ are the lower and upper semi-variance from benchmark $\mathrm{B}$, respectively (in square $\mathrm{USD}) ; \tau_{\mathrm{dr}}$ and $\tau_{\text {up }}$ are the tolerance (or indifference) levels to downside risk and upside potential, respectively (in USD). Note that decisions based on EMV are a particular case of equation (2), where decision makers are neutral to downside risk and upside potential (i.e., $\tau_{\mathrm{dr}}=\tau_{\mathrm{up}} \rightarrow \infty$ ). 

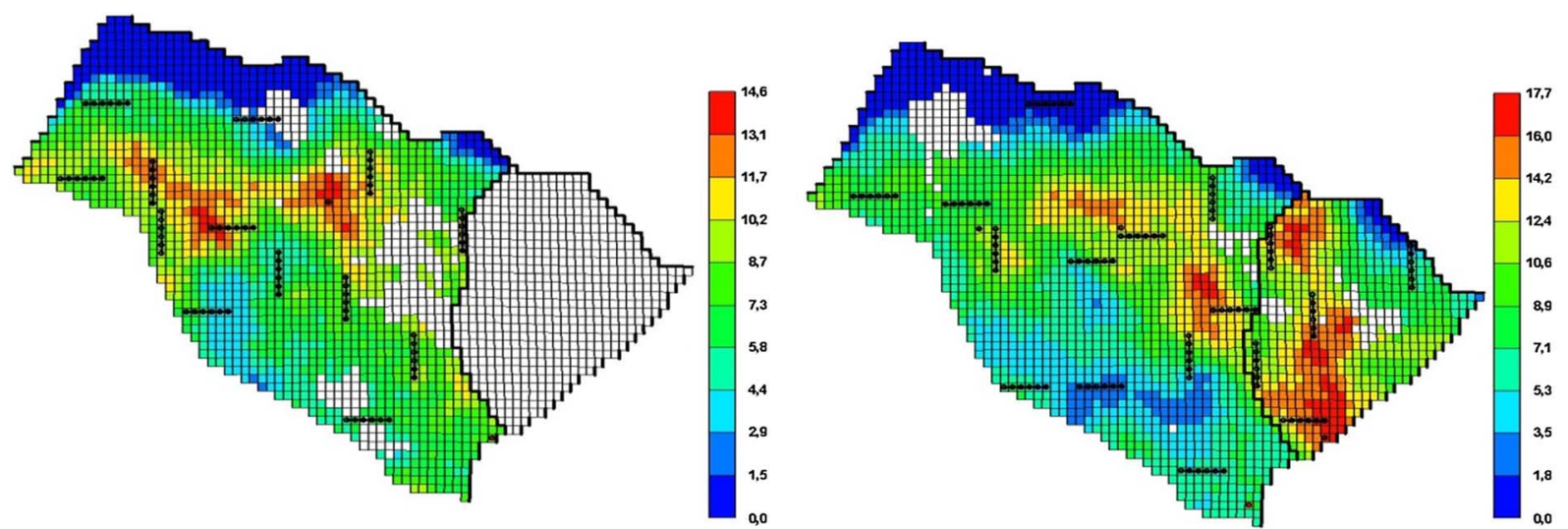

Fig. 11. Map of total oil per unit area at the beginning of the prediction period of RM7 with production strategy E7 (left) and RM9 with production strategy E9 (right).

Equation (2) uses lower semi-deviation from benchmark return B (eq. (3)) to quantify downside risk, and upper semi-deviation from B (eq. (4)) to quantify upside potential:

$$
\begin{aligned}
& \mathrm{S}_{\mathrm{B}-}=\sqrt{\mathrm{S}_{\mathrm{B}-}^{2}}=\sqrt{\mathrm{E}\left\{\min [(\mathrm{NPV}-\mathrm{B}), 0]^{2}\right\}}, \\
& \mathrm{S}_{\mathrm{B}+}=\sqrt{\mathrm{S}_{\mathrm{B}+}^{2}}=\sqrt{\mathrm{E}\left\{\max [(\mathrm{NPV}-\mathrm{B}), 0]^{2}\right\}},
\end{aligned}
$$

where $\mathrm{S}_{\mathrm{B}-}$ is the lower semi-deviation from benchmark $\mathrm{B}$; $\mathrm{S}_{\mathrm{B}-}^{2}$ is the lower semi-variance from $\mathrm{B} ; \mathrm{S}_{\mathrm{B}+}$ is the upper semi-deviation from $\mathrm{B} ; \mathrm{S}_{\mathrm{B}+}^{2}$ is the upper semi-variance from $\mathrm{B}$; $\mathrm{E}$ is the expectation operator; and NPV is the net present value.

The benchmark (B) is defined by the decision maker as it depends solely on his/her definition of loss and gain. However, note that all production strategies must use the same benchmark for impartiality. Here, we set the benchmark as the EMV of production strategy E1, optimized for the Base Case, and defined $\tau_{\mathrm{dr}}$ and $\tau_{\mathrm{up}}$ as a function of this value. For this synthetic case study, we considered a fictitious decision maker averse to downside risk and willing to exploit the upside potential $\left(\tau_{\mathrm{dr}}=\tau_{\mathrm{up}}=0.4 \times \mathrm{B} \approx\right.$ USD 700 million).

In Table 5 and Figure 13, we evaluate and compare the nine production strategies (E1-E9) and the robust strategy (EMR), with and without economic uncertainty. EMR is the best production strategy under uncertainty. From the set of nine alone, E9 is the best. Production strategies E3, $\mathrm{E} 6$, and $\mathrm{E} 7$, optimized for RMs without hydrocarbons in the East block, are the least attractive alternatives considering the 214 scenarios simultaneously.

\subsection{Step 11}

Step 11 consists of detailed analyses of the best strategy obtained in Step 10.

\subsubsection{Managing uncertainty}

The best strategy can be improved to better manage uncertainty, considering the company's risk attitude. The most

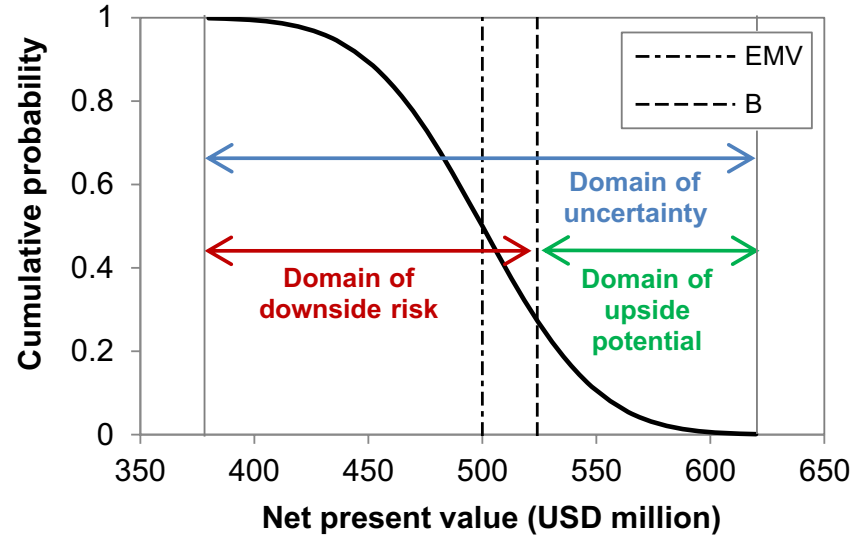

Fig. 12. Hypothetical NPV risk curve, highlighting three domains of variability: overall uncertainty (blue), downside risk (red), and upside potential (green). EMV is the expected monetary and B the benchmark return (modified from Santos et al., 2017a).

common actions are (1) acquiring information, to reduce reservoir uncertainty, (2) adding flexibility to the system, to allow system modifications as uncertainty unfolds over time, and (3) increasing robustness (an automated procedure was addressed in Step 10, here we discuss a manual procedure). Despite reducing risks and increasing the EMV, these approaches incur investment and costs and may delay production. Therefore, before making a decision, their benefits should be quantified using the Expected Value of Information (EVoI) and Expected Value of Flexibility $(\mathrm{EVoF})$.

The petroleum literature provides many methods to estimate the EVoI and the EVoF. In related works (Santos et al., 2017b; Santos et al., 2018a), we showed how these can become fully automated procedures when integrated into the 12-step decision structure, as exemplified in Figure 14 for EVoI.

The automated EVoI and EVoF analyses use the following as input: (1) the set of uncertain scenarios that match production data (obtained in Step 5), (2) the set of 
Table 5. Evaluation of the nine specialized production strategies (E1-E9) and robust strategy (EMR). Values in USD million.

\begin{tabular}{|c|c|c|c|c|c|c|c|c|}
\hline \multirow{2}{*}{$\begin{array}{l}\text { Production } \\
\text { strategy }\end{array}$} & \multicolumn{4}{|c|}{ Without economic uncertainty } & \multicolumn{4}{|c|}{ With economic uncertainty } \\
\hline & EMV & $\mathrm{S}_{\mathrm{B}-}$ & $\mathrm{S}_{\mathrm{B}+}$ & $\overline{\varepsilon(\mathrm{NPV})}$ & EMV & $\mathrm{S}_{\mathrm{B}-}$ & $\mathrm{S}_{\mathrm{B}+}$ & $\varepsilon(\mathrm{NPV})$ \\
\hline E1 & 1581 & 329 & 308 & 1561 & 1720 & 443 & 552 & 1875 \\
\hline $\mathrm{E} 2$ & 1596 & 343 & 348 & 1601 & 1735 & 453 & 578 & 1919 \\
\hline E3 & 974 & 739 & 34 & 196 & 1075 & 848 & 178 & 92 \\
\hline E4 & 1556 & 383 & 361 & 1532 & 1696 & 492 & 585 & 1841 \\
\hline E5 & 1526 & 437 & 365 & 1443 & 1665 & 539 & 590 & 1747 \\
\hline E6 & 1142 & 582 & 68 & 665 & 1253 & 702 & 244 & 635 \\
\hline E7 & 1265 & 446 & 67 & 987 & 1382 & 582 & 276 & 1007 \\
\hline E8 & 1548 & 441 & 396 & 1494 & 1694 & 543 & 629 & 1838 \\
\hline E9 & 1675 & 327 & 439 & 1798 & 1825 & 435 & 682 & 2220 \\
\hline EMR & 1739 & 244 & 408 & 1892 & 1889 & 379 & 688 & 2360 \\
\hline
\end{tabular}
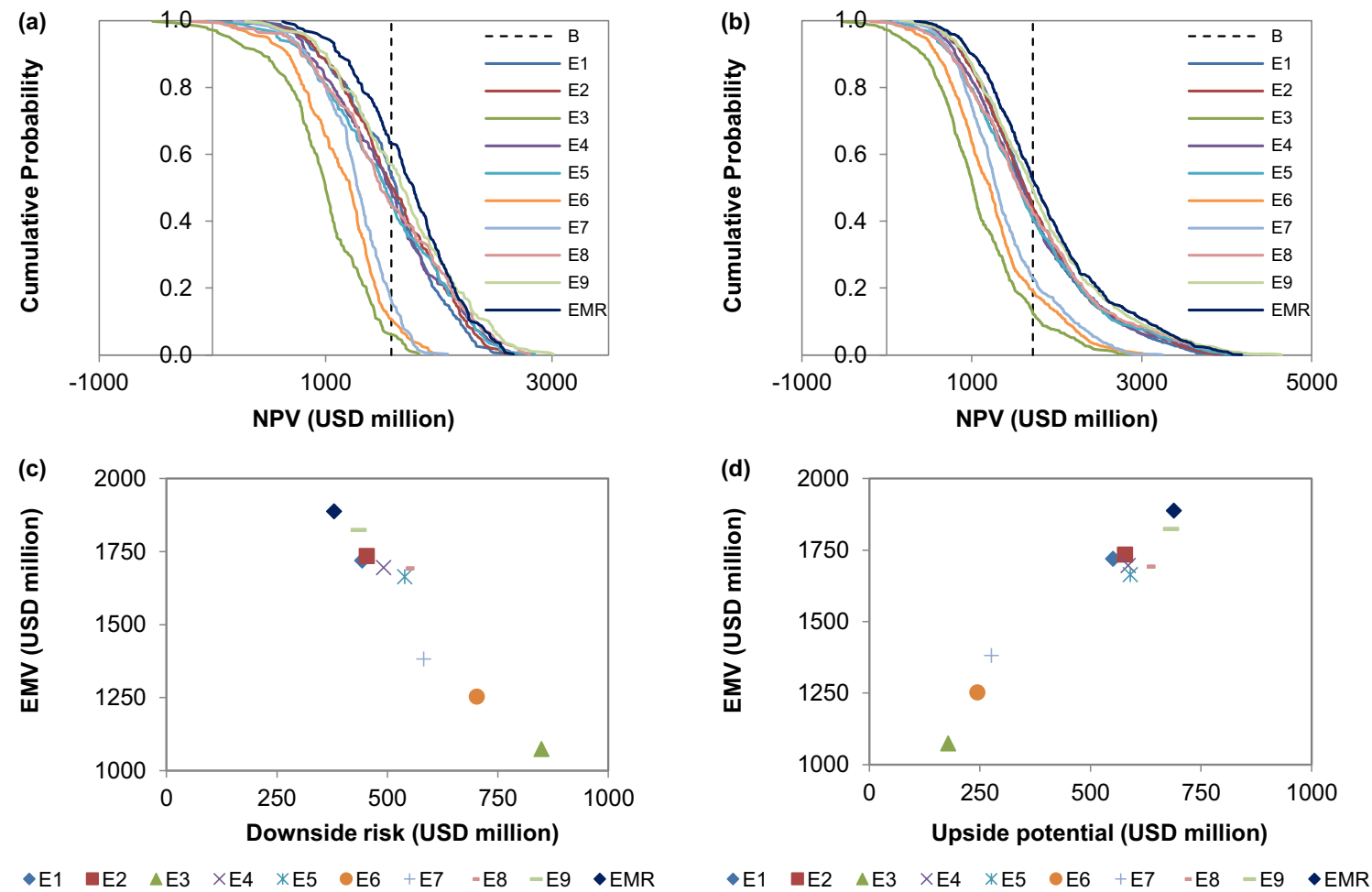

Fig. 13. NPV risk curves for the nine specialized production strategies (E1-E9) and robust strategy (EMR), considering 214 uncertain scenarios with a) deterministic economic scenario, and b) three uncertain economic scenarios. The vertical dashed line is the benchmark (B). Cross-plots of c) Expected Monetary Value (EMV) versus downside risk, and d) EMV versus upside potential, both under economic uncertainty.

specialized production strategies, optimized individually for each RM (obtained in Step 9), and (3) the robust production strategy, optimized probabilistically for all RMs simultaneously (obtained in Step 10).

The use of a robust production strategy is optional for EVoI, where we aim to learn the most-likely reservoir scenario so that we can implement a specialized production strategy. However, considering a robust production strategy is important for cases with high uncertainty, where a single source of information may be insufficient to reduce all uncertainties. In such cases, the use of a robust production strategy in the EVoF study is highly 


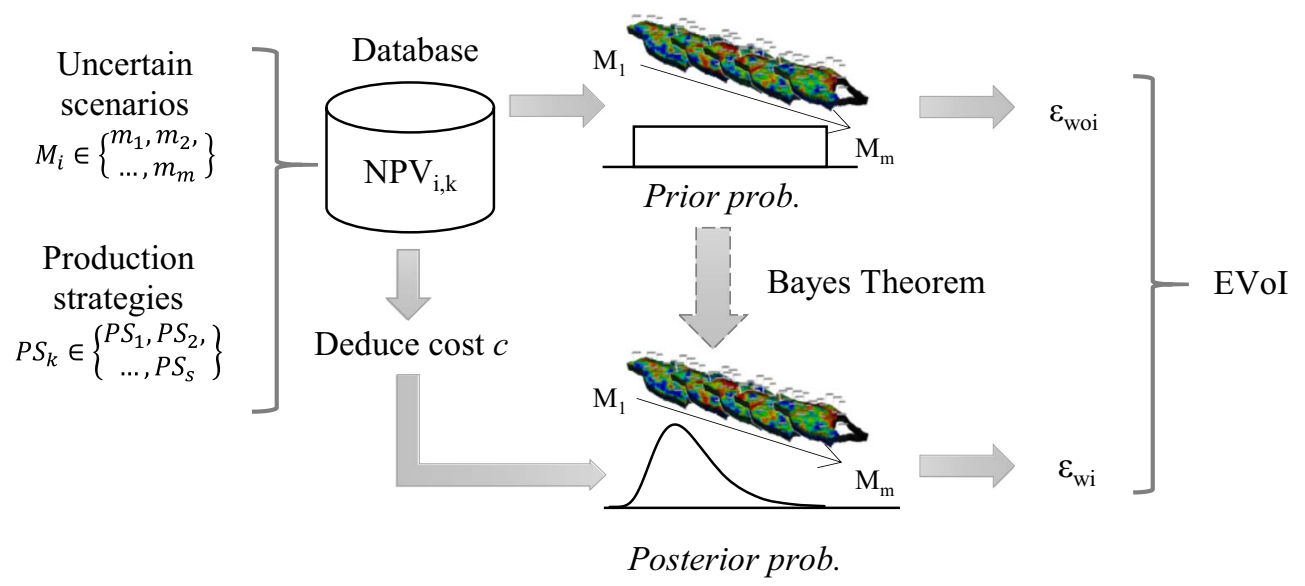

Fig. 14. Automated procedure for EVoI analysis integrated into the 12-step decision-structure.

recommended to define the rigid attributes of the production strategy.

As the set of RMs represents the uncertain system, their respective strategies quantify the possibilities to develop the field, namely number and placement of wells, platform size, and fluid processing capacities. Thus, these strategies are indicators for the degree and type of flexibility required by the system. The flexible strategy is defined in an iterative procedure that combines features of the robust strategy (e.g., well placement) and flexible features from the differences between specialized strategies (e.g., available slots for connection of additional wells).

\subsubsection{Determining the EVol of an appraisal well}

We considered drilling an appraisal well to gather information on the presence or absence of hydrocarbons in the East block (BL) and the Water-Oil Contact (WOC), simultaneously. We estimated EVoI for perfect information $(100 \%$ reliable when interpreting $\mathrm{BL}$ and WOC) and imperfect information (95\% reliable when interpreting BL, and $80 \%$ for WOC). Without further information, EMR is chosen (Tab. 5).

We determined the value of the project with information using equation (2) with the EMV of E1 as the benchmark, the same used in the case without information. We considered three economic scenarios.

Using equation (2) for project evaluation, $\mathrm{EVoI}$ is given by equation (5), where $\varepsilon(\mathrm{NPV})_{\text {wi }}$ is the value of the project with information and $\varepsilon(\mathrm{NPV})_{\text {woi }}$ is the value of the project without information. Because of the non-linearity of $\varepsilon$, the cost of information must be deduced to the NPV values stored in the database before estimating $\varepsilon(\mathrm{NPV})_{\text {wi: }}$

$$
\mathrm{EVOI}_{\varepsilon}=\varepsilon(\mathrm{NPV})_{\mathrm{wi}}-\varepsilon(\mathrm{NPV})_{\mathrm{woi}} .
$$

We also calculate the EVoI as the expected increase in EMV (eq. (6)), which is a particular case of equation (5), where decision makers are neutral to downside risk and upside potential $\left(\tau_{\mathrm{dr}}=\tau_{\mathrm{up}} \rightarrow \infty\right)$ :

$$
\mathrm{EVOI}_{\mathrm{EMV}}=\mathrm{EMV}_{\mathrm{wi}}-\mathrm{EMV}_{\mathrm{woi}} \text {. }
$$

We determined the EVoI using the pre-existing set of 214 scenarios matching production data, with updated probabilities using Bayes Theorem. That is, the 214 equiprobable scenarios are used to estimate $\varepsilon(\mathrm{NPV})_{\text {woi }}$ and the 214 scenarios with updated probabilities for BL and WOC are used to estimate $\varepsilon(\mathrm{NPV})_{\text {wi }}$.

In this application, we assumed that information could be acquired without delaying the development plan and that the appraisal well would be used for field development. Thus, the cost of this well is already included in the NPV values of most production strategies (E1, E2, E4, E5, E8, E9, those with wells planed for the East block). Aiming for a first assessment, we used the NPV values directly in the automated procedure, meaning that we only update the probability of occurrence of each scenario. This first approximate is not the true EVoI but provides an initial diagnosis. If it reveals that the information source has potential, a more precise EVoI calculation should be performed.

Table 6 shows EVoI calculated with equations (5) and (6). Note that equation (5) improved the EVoI estimate by accounting for all changes in the risk curve, not only the increased EMV but also the decreased downside risk and increased upside potential. Thus, equation (6) underestimated the EVoI.

Table 7 shows the best production strategy for each information outcome. We observed that the robust strategy EMR is the best decision for many information outcomes, meaning that strong uncertainty remains after information acquisition (other attributes besides BL and WOC). This conclusion is only possible because we used the 214 scenarios to determine the EVoI, meaning that we accounted for the effects of all mapped uncertainties, and not only BL and WOC.

\subsubsection{Refining the best strategy for further improvements}

For complex problems with a large search space, automatic procedures often yield local maxima. As Step 11 is manual, local minima can be avoided. We can check for misconceptions from previous automated steps, as shown by Santos et al. (2017c). The authors used several indicators to assess 
Table 6. EVoI for an appraisal well to assess the uncertainties BL and WOC. Values in USD million.

\begin{tabular}{|c|c|c|c|c|c|c|c|c|c|c|}
\hline & \multicolumn{4}{|c|}{ With information } & \multicolumn{4}{|c|}{ Without information } & \multirow[b]{2}{*}{$\mathrm{EVoI}_{\varepsilon}$} & \multirow[b]{2}{*}{$\mathrm{EVoI}_{\mathrm{EMV}}$} \\
\hline & EMV & $\mathrm{S}_{\mathrm{B}-}$ & $\mathrm{S}_{\mathrm{B}+}$ & $\varepsilon(\mathrm{NPV})_{\mathrm{wi}}$ & EMV & $\mathrm{S}_{\mathrm{B}-}$ & $\mathrm{S}_{\mathrm{B}+}$ & $\varepsilon(\mathrm{NPV})_{\text {woi }}$ & & \\
\hline Perfe & $\begin{array}{c}1922 \\
(+1.8 \%)\end{array}$ & $\begin{array}{c}376 \\
(-1.0 \%)\end{array}$ & $\begin{array}{c}728 \\
(+5.8 \%)\end{array}$ & $\begin{array}{c}2478 \\
(+5.0 \%)\end{array}$ & 1889 & 379 & 689 & 2360 & 118 & 34 \\
\hline $\begin{array}{l}\text { Imperfect information } \\
(95 \% \mathrm{bl}, 80 \% \mathrm{wo})\end{array}$ & $\begin{array}{c}1910 \\
(+1.2 \%)\end{array}$ & $\begin{array}{c}378 \\
(-0.4 \%)\end{array}$ & $\begin{array}{c}716 \\
(+4.1 \%)\end{array}$ & $\begin{array}{c}2440 \\
(+3.4 \%)\end{array}$ & 1889 & 379 & 689 & 2360 & 80 & 22 \\
\hline
\end{tabular}

Table 7. Best production strategy according to information outcomes.

\begin{tabular}{|c|c|c|}
\hline $\begin{array}{l}\text { Appraisal well } \\
\text { indicates }\end{array}$ & $\begin{array}{c}\text { Well logs indicate the } \\
\text { depth of water-oil } \\
\text { contact }\end{array}$ & $\begin{array}{l}\text { Best } \\
\text { production } \\
\text { strategy is }\end{array}$ \\
\hline \multirow{5}{*}{$\begin{array}{l}\text { Hydrocarbons } \\
\text { present in the East } \\
\text { block }\end{array}$} & $3174 \mathrm{~m}(\operatorname{woc} 0)$ & EMR \\
\hline & 3074 m (woc1) & EMR \\
\hline & $3124 \mathrm{~m}$ (woc2) & EMR \\
\hline & 3224 m (woc3) & E9 \\
\hline & $3274 \mathrm{~m}$ (woc4) & E9 \\
\hline \multirow{5}{*}{$\begin{array}{l}\text { Hydrocarbons } \\
\text { absent in the East } \\
\text { block }\end{array}$} & $3174 \mathrm{~m}($ woc0) & EMR \\
\hline & 3074 m (woc1) & EMR \\
\hline & $3124 \mathrm{~m}$ (woc2) & EMR \\
\hline & $3224 \mathrm{~m}$ (woc3) & EMR \\
\hline & $3274 \mathrm{~m}$ (woc4) & EMR \\
\hline
\end{tabular}

the performance of E9 over the 214 scenarios, aiming to increase its robustness. The remaining strategies E1 through E8 served as boundaries for the different variables, such as platform size and number of wells. Ultimately, the authors observed that many of the horizontal producers had been placed in a suboptimal layer of the reservoir, further improving the automated optimization procedure (production strategy R4) (Fig. 15).

\subsubsection{Integration with production facilities}

As mentioned in Step 6, the integration of reservoir and production systems can improve production forecasts. As the integration increases computation time, it is important to assess the need for this integration and to use a suitable methodology (in this application, we used approximate boundary conditions in Step 6 and applied the integration in Step 11 only).

von Hohendorff Filho and Schiozer (2017) analyzed the influence of this integration, evaluating its effects on the production strategy parameters. The integration was applied to E9 for RM9 as an integrated production development, resulting in a lower initial NPV.

We re-optimized E9 altering configurations related to platform position, pipe diameters, gas lift rates, platform capacities, and the number, schedule, placement and shut-in times of wells. Figure 16 shows how NPV and
ORF were affected during the global optimization for the best integrated production strategy. The optimization shows that standalone E9 is not the optimal strategy for integrated RM9.

Comparing standalone and integrated production strategies, we observed important changes in number and placement of wells that indicate the need to integrate reservoir and production models. Specific variables from production systems such as pipe diameters and gas lift rates also had a great impact, indicating the need to couple reservoir and production system models to reach more robust results.

The optimized integrated systems resulted in significantly increased NPVs, maintaining the same oil recovery factor while requiring a lower initial investment. These results demonstrate the benefits of integrating reservoir and production systems to increase robustness for decision making.

\subsection{Step 12 and discussions}

Steps 1-11 deliver a robust process to be used in the decision analysis, yielding an appropriate strategy that honors the history data and considers all uncertainties. At the end of the twelve steps, decision makers have technical and economic indicators to support both long-term, modelbased decisions and short-term, data-driven decisions. This flexible 12-step procedure is suitable for companies with different aims as the process is guided by the objective: model quality, the necessity for further data assimilation (history matching), objective function selection, etc.

The 12-step procedure must be repeated whenever new important information is obtained and, therefore, is a continuous and iterative process. The most critical time is, of course, when the development is prepared and the production facilities selected. The number and placement of wells are important outputs of this analysis but the procedure can also be useful at later stages for real-time reservoir management. Readers interested in the management phase are referred to the case study UNISIM-I-M (Gaspar et al., 2016b).

The Robust Optimization, the optimization problem formulated under uncertainty to maximize a probabilistic objective function, ensured the best performance under uncertainty, considering the EMV, downside risk, and upside potential. However strong in robustness, this single production strategy gives little information on the different possibilities of field development, such as number and placement of wells, and platform processing capacities. 

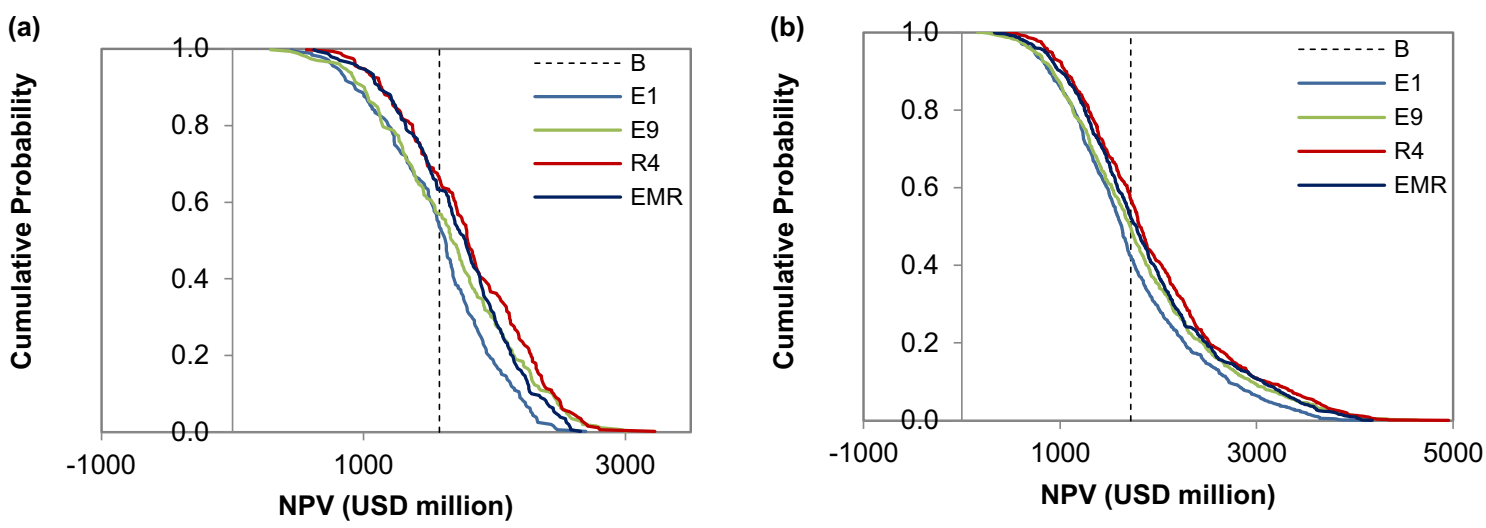

Fig. 15. NPV risk curves for the production strategy of the base case (E1), the best specialized production strategy (E9), the robust strategy obtained through a robust optimization procedure (EMR), and a robust strategy obtained by manually improving E9 (R4): a) NPV without economic uncertainty; and b) NPV with economic uncertainty.
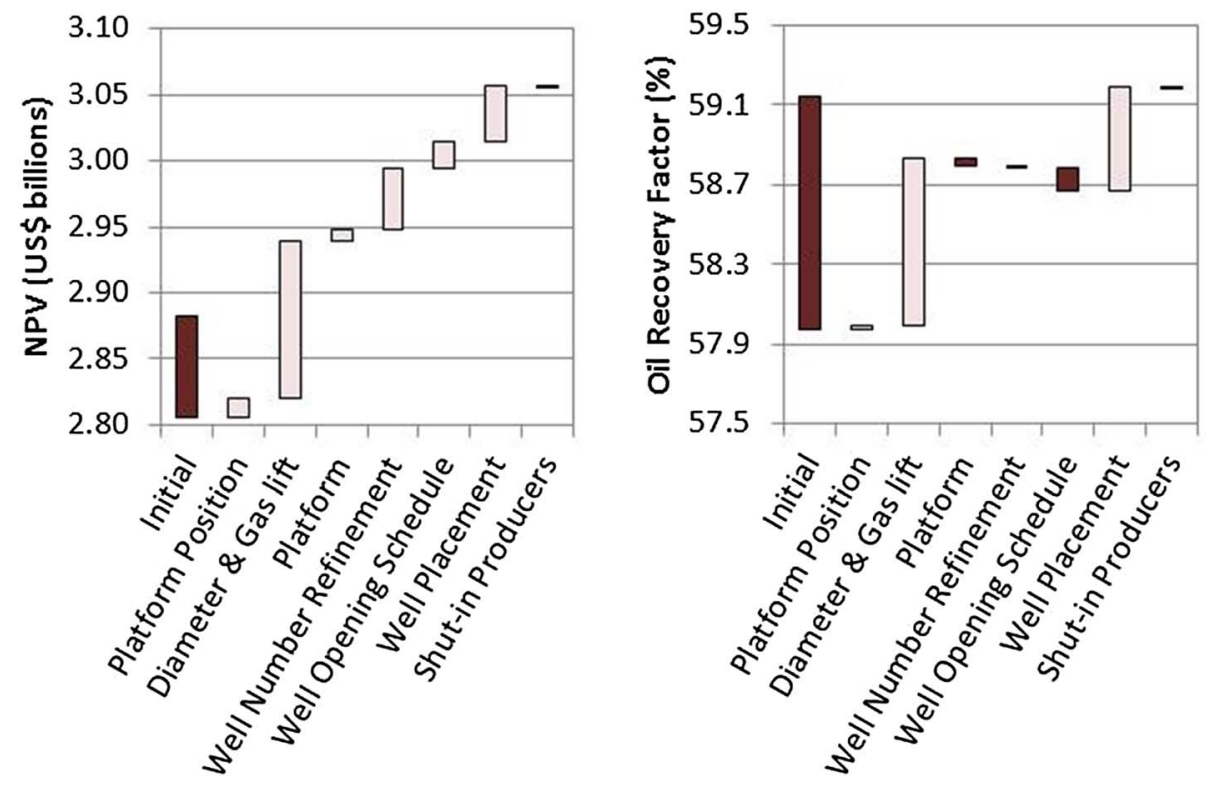

Fig. 16. NPV and oil recovery factor variations for best optimized strategy.

Conversely, these data can be retrieved from the production strategies optimized individually for each RM. This approach gives decision makers an objective assessment of how different (or similar) these alternatives are, which provides valuable insights for $\mathrm{EVOI}$ and $\mathrm{EVoF}$ studies. In addition, as extensive optimization procedures were unnecessary in this final step, the analyses were automated. This automation is particularly important for EVoI, as it facilitates the assessment of the value of perfect and imperfect information, for varying degrees of information reliability. Note that, although we aim to automate as many procedures as possible, we recognize that manual refinement procedures can be valuable to investigate possible misconceptions or avoid local maxima of optimization processes with large search spaces.

We showed that specialized (deterministic) optimization can be advantageous in decision and risk analyses, provided that it is part of a probabilistic process $(i . e$. , it is not limited to the most likely scenario). However, note that an adequate RM selection must be guaranteed, representing system inputs (probability distribution of uncertain attributes) and outputs (variability in production, injection, and economic forecasts). Furthermore, we showed that robust and specialized optimizations are complementary approaches in the decision-analysis process, and our current recommendation is to perform both in a case study. As this can be computationally demanding, the decision to choose one type of optimization over the other depends on the company's objectives. Future research is planned on methods to make conducting both approaches computationally feasible for day-to-day applications.

In our case study, we used the proposal by Meira et al. (2016) to select the RMs. The attractiveness of this proposal is that it ensures that the set of RMs represents 
uncertainty in both system inputs and outputs. Ease-of-use is guaranteed as the method is software based, RMFinder. At the time of this study, we applied the initial proposal of RMFinder (Meira et al., 2016), which had some simplifications, namely the set of RMs were assumed to be equiprobable and it only considered a maximum of four field indicators (e.g., NPV, $\left.N_{\mathrm{p}}, W_{\mathrm{p}}, \mathrm{ORF}\right)$. Meira et al. (2017) improved RMFinder by assigning probabilities to each RM. Further improvements are still ongoing, such as increasing the number of objective functions (up to 50), including not only field indicators, but also well indicators (such as fluid rates and BHP).

From previous studies for different case studies, we observed that around nine RMs are sufficient for production strategy selection. Future research is currently being conducted on the optimal number of RMs and candidate production strategies applied to studies of information acquisition, robustness, and flexibility, and on the possible loss of precision that this simplification may cause.

Some probabilistic analyses of this study used the full set of hundreds of scenarios matching production data. Although ensuring the most accurate predictions possible, this approach is computationally demanding and potentially unfeasible for simulation models with a very high runtime. Thus, it is important to define an objective and the necessary precision in Step 2. We are currently conducting research on assessing the feasibility of performing all probabilistic-based analyses on a small subset of RMs, each characterized by a probability of occurrence.

Our case study was in an early development phase, meaning that model updating was conducted with limited production data (four years of production data for four production wells). However, the 12-step method is not limited to such cases and can be applied to fields with many years of production data from producers and injectors, as demonstrated by Soares et al. (2018).

Data-driven, short-term decisions were not included in this work because they are more appropriate to a field in the management phase.

\section{Conclusion}

We have presented a model-based, closed-loop methodology based on twelve steps to be used in decision analysis for petroleum reservoir development and management under uncertainties, covering both model updating and production optimization.

Companies often skip several steps to expedite projects but we believe that, with the simplification presented here, the methodology is applicable to real cases, including complex cases with long simulation runtimes, and still ensure reliable decisions. In such a case, it is possible to decrease the number of simulations in Steps 6, 7 and 9 and select a smaller number of representative models (Step 8).

Note that further simplifications can yield suboptimal decisions. The level of detail of each step is a function of the importance of the study, the complexity of the case, and the available resources and time. The most timeconsuming part is the optimization of the production strategy and the results are a function of the quality of this process; therefore, it is important to use computationally efficient optimization processes.

The methodology is flexible enough to be applied to reservoirs in different stages of their lifetime. We presented a case in the development phase but it can be used at other stages. It is also simple enough to be used in practical applications because it does not require proxy models or complex tools.

By providing a comprehensive decision structure that integrates reservoir characterization, data assimilation, and production optimization, our method works as the core basis for specialized methodologies for each of these domains, as our results have shown.

Acknowledgments. This work was conducted with the support of Energi Simulation and Petrobras within the ANP R\&D tax as "commitment to research and development investments". The authors are grateful for the support of the Center of Petroleum Studies (CEPETRO-UNICAMP/Brazil), the Department of Energy (DE-FEM-UNICAMP/Brazil) and the Research Group in Reservoir Simulation and Management (UNISIMUNICAMP/Brazil). In addition, special thanks to $C M G$ and Schlumberger for software licenses and technical support.

\section{References}

Aliyev E., Durlofsky L.J. (2015) Multilevel field development optimization under uncertainty using a sequence of upscaled models, Math. Geosci. 49, 3, 1-33. https://doi.org/10.1007/ s11004-016-9643-0.

Avansi G., Rios V., Schiozer D.J. (2019) Numerical tuning in reservoir simulation: It is worth the effort in practical petroleum applications, Braz. Soc. Mech. Sci. Eng. 41, 59. https://doi.org/10.1007/s40430-018-1559-9.

Avansi G.D., Schiozer D.J. (2015a) A new approach to history matching using reservoir characterization and reservoir simulation integrated studies, in: Offshore Technology Conference, 4-7 May, Houston, Texas. https://doi.org/10.4043/26038-MS.

Avansi G.D., Schiozer D.J. (2015b) UNISIM-I: Synthetic model for reservoir development and management applications, Int. J. Model. Sim. Petrol. Ind. 9, 1, 21-30.

Bertolini A.C., Maschio C., Schiozer D.J. (2015) A methodology to evaluate and reduce reservoir uncertainties using multivariate distribution, J. Petrol. Sci. Eng. 128, 1-14. https://doi.org/10.1016/j.petrol.2015.02.003.

Botechia V.E., Gaspar A.T.F.S., Avansi G.D., Davolio A., Schiozer D.J. (2018a) Investigation of production forecast biases of simulation models in a benchmark case, Oil Gas Sci. Technol. - Rev. IFP Energies nouvelles 73, 23. https://doi. org/10.2516/ogst/2018014.

Botechia V.E., Dos Santos D.R., Barreto C.E.A., Gaspar A.T.F.S., Santos S.M.G., Schiozer D.J. (2018b) Estimating the chance of success of information acquisition for the Norne benchmark case, Oil Gas Sci. Technol. - Rev. IFP Energies nouvelles 73, 54. https://doi.org/10.2516/ogst/2018054.

Chen Y., Oliver D.S., Zhang D. (2009) Efficient ensemble-based closed-loop production optimization, SPE J. 14, 4, 634-645. https://doi.org/10.2118/112873-PA.

Correia M.G., Maschio C., Schiozer D.J. (2015) Integration of multiscale carbonate reservoir heterogeneities in reservoir 
simulation, J. Petrol. Sci. Eng. 131, 34-50. https://doi.org/ 10.1016/j.petrol.2015.04.018.

Correia M.G., Filho J.H., Schiozer D.J. (2018a) An integrated workflow to combine static and dynamic uncertainties in reservoir simulation models, in: 80th EAGE Conference and Exhibition 2018, 11-14 June, Copenhagen, Denmark. https://doi.org/10.3997/2214-4609.201800807.

Correia M.G., Maschio C., Schiozer D.J. (2018b) Flow simulation using local grid refinements to model laminated reservoirs, Oil Gas Sci. Technol. - Rev. IFP Energies nouvelles 73, 5. https://doi.org/10.2516/ogst/2017043.

Costa L.A.N., Maschio C., Schiozer D.J. (2018) A new methodology to reduce uncertainty of global attributes in naturally fractured reservoirs, Oil Gas Sci. Technol. - Rev. IFP Energies nouvelles 73, 41. https://doi.org/10.2516/ogst/2018038.

Costa A.P., Schiozer D.J., Moczydlower P., Bedrikovetsky P. (2008) Use of representative models to improve the decision making process of chemical flooding in a mature field, in: $S P E$ Russian Oil and Gas Technology Conference and Exhibition, 28-30 October, Moscow, Russia. https://doi.org/10.2118/ 115442-MS.

Davolio A., Schiozer D.J. (2018) Probabilistic seismic history matching using binary images, J. Geophys. Eng. 15, 1, 261-274. https://doi.org/10.1088/1742-2140/aa99f4.

de Neufville R. (2004) Uncertainty management for engineering systems planning and design, in: Engineering Systems Symposium, 29-31 March, Cambridge, MA.

Douarche F., Da Veiga S., Feraille M., Enchéry G., Touzani S., Barsalou R. (2014) Sensitivity analysis and optimization of surfactant-polymer flooding under uncertainties, Oil Gas Sci. Technol. - Rev. IFP Energies nouvelles 69, 4, 603-617. https://doi.org/10.2516/ogst/2013166.

Durlofsky L.J. (1997) Use of higher moments for the description of upscaled, process independent relative permeabilities, SPE J. 2, 4, 474-484. https://doi.org/10.2118/37987-PA.

Durlofsky L.J. (1998) Coarse scale models of two phase flow in heterogeneous reservoirs: Volume averaged equations and their relationship to existing upscaling techniques, Comput. Geosci. 2, 2, 73-92. https://doi.org/10.1023/A: 1011593901771.

Feraille M. (2013) An optimization strategy based on the maximization of matching-targets' probability for unevaluated results, Oil Gas Sci. Technol. - Rev. IFP Energies nouvelles 68, 3, 545-556. https://doi.org/10.2516/ogst/2012079.

Feraille M., Marrel A. (2012) Prediction under uncertainty on a mature field, Oil Gas Sci. Technol. - Rev. IFP Energies nouvelles 67, 2, 193-206. https://doi.org/10.2516/ogst/2011172.

Gaspar A.T.F., Barreto C.E.A., Schiozer D.J. (2016a) Assisted process for design optimization of oil exploitation strategy, $J$. Pet. Sci. Eng. 146, 473-488. https://doi.org/10.1016/j.petrol. 2016.05.042.

Gaspar A.T.F.S., Avansi G.D., Maschio C., Santos A.A.S., Schiozer D.J. (2016b) UNISIM-I-M: Benchmark case proposal for oil reservoir management decision-making, in: SPE Energy Resources Conference, 13-15 June, Port of Spain, Trinidad and Tobago. https://doi.org/10.2118/180848-MS.

Gaspar A.T.F.S., Avansi G.D., Santos A.A., Hohendorff Filho J.C., Schiozer D.J. (2015) UNISIM-I-D: Benchmark studies for oil field development and production strategy selection, Int. J. Model. Sim. Petrol. Ind. 9, 1, 47-55.

Gaspar A.T.F.S., Barreto C.E.A.G., Munhoz Mazo E.O., Schiozer D.J. (2014) Application of assisted optimization to aid oil exploitation strategy selection for offshore fields, in: SPE Latin America and Caribbean Petroleum Engineering Conference, 21-23 May, Maracaibo, Venezuela. https://doi. org $/ 10.2118 / 169464-$ MS.

Helton J.C., Davis F.J. (2003) Latin hypercube sampling and the propagation of uncertainty in analyses of complex systems, Reliab. Eng. Syst. Safe 81, 1, 23-69. https://doi.org/10.1016/ S0951-8320(03)00058-9.

Imrie C.E., Macrae E.J. (2016) Application of experimental design to estimate hydrocarbons initially in place, Pet. Geosci. 22, 1, 11-19. https://doi.org/10.1144/petgeo2014-071.

Jansen J.-D., Brouwer D.R., Douma S.G. (2009) Closed-loop reservoir management, in: SPE Reservoir Simulation Symposium, 2-4 February, The Woodlands, Texas. https://doi.org/ 10.2118/119098-MS.

Jansen J.-D., Brouwer D.R., Nævdal G., van Kruijsdijk C.P.J. W. (2005) Closed-loop reservoir management, First Break 23, 1, 43-48. https://doi.org/10.3997/1365-2397.2005002.

Jiang R., Stern D., Halsey T.C., Manzocchi T. (2016) Scenario discovery workflow for robust petroleum reservoir development under uncertainty, Int. J. Uncertain. Quan. 6, 6, 533-559. https://doi.org/10.1615/Int.J.UncertaintyQuantification. 2016018932.

Lodoen O.P., Omre H. (2008) Scale-corrected ensemble Kalman filtering applied to production-history conditioning in reservoir evaluation, SPE J. 13, 2, 177-194. https://doi.org/ 10.2118/111374-PA.

Mahjour S.K., Correia M.G., dos Santos A.A.D.S., Schiozer D.J. (2019) Developing a workflow to represent fractured carbonate reservoirs for simulation models under uncertainties based on flow unit concept, Oil Gas Sci. Technol. - Rev. IFP Energies nouvelles 74, 15. https://doi.org/10.2516/ogst/2018096.

Maschio C., Schiozer D.J. (2008) A new methodology for assisted history matching using independent objective functions, Petrol. Sci. Technol. 26, 9, 1047-1062. https://doi.org/ 10.1080/10916460701208389.

Maschio C., Schiozer D.J. (2015) A new optimization framework using genetic algorithm and artificial neural network to reduce uncertainties in petroleum reservoir models, Eng. Optimiz. 47, 1, 72-86. https://doi.org/10.1080/0305215X.2013.868453.

Maschio C., Schiozer D.J. (2016) Probabilistic history matching using discrete latin hypercube sampling and nonparametric density estimation, J. Pet. Sci. Eng. 147, 98-115. https://doi. org/10.1016/j.petrol.2016.05.011.

Meira L.A., Coelho G.P., Santos A.A.S., Schiozer D.J. (2016) Selection of representative models for decision analysis under uncertainty, Comput. Geosci. 88, 67-82. https://doi.org/ 10.1016/j.cageo.2015.11.012.

Meira L.A., Coelho G.P., Silva C.G., Schiozer D.J., Santos A.A. S. (2017) RMFinder 2.0: An improved interactive multicriteria scenario reduction methodology, in: SPE Latin America and Caribbean Petroleum Engineering Conference, 17-19 May, Buenos Aires, Argentina. https://doi.org/ 10.2118/185502-MS.

Mishra S. (1998) Alternatives to Monte-Carlo simulation for probabilistic reserves estimation and production forecasting, in: SPE Annual Technical Conference and Exhibition, 27-30 September, New Orleans, Louisiana. https://doi.org/10.2118/ 49313-MS.

Nævdal G., Brouwer D.R., Jansen J.-D. (2006) Waterflooding using closed-loop control, Comput. Geosci. 10, 1, 37-60. https://doi.org/10.1007/s10596-005-9010-6. 
Oliveira G.S., Maschio C., Schiozer D.J. (2018) A new approach with multiple realizations for image perturbation using cosimulation and probability perturbation method, Oil Gas Sci. Technol. - Rev. IFP Energies nouvelles 73, 68. https://doi. org $/ 10.2516 /$ ogst $/ 2018065$.

Osterloh W.T. (2008) Use of multiple-response optimization to assist reservoir simulation probabilistic forecasting and history matching, in: SPE Annual Technical Conference and Exhibition, 24 September, Denver, Colorado. https://doi.org/ 10.2118/116196-MS.

Panjalizadeh H., Alizadeh N., Mashhadi H. (2014) A workflow for risk analysis and optimization of steam flooding scenario using static and dynamic proxy models, J. Petrol. Sci. Eng. 121, 78-86. https://doi.org/10.1016/j.petrol.2014.06.010.

Preux C. (2016) About the use of quality indicators to reduce information loss when performing upscaling, Oil Gas Sci. Technol. - Rev. IFP Energies nouvelles 71, 7. https://doi. org/10.2516/ogst/2014023.

Ravagnani A.T.F.S.G., Mazo E.O.M., Schiozer D.J. (2011) A case study of the structure of the process for production strategy selection, Int. J. Model. Sim. Petrol. Ind. 4, 1, 9-15.

Risso F., Risso V., Schiozer D.J. (2011) Risk analysis of petroleum fields using latin hypercube, Monte Carol [sic] and derivative tree techniques, J. Petrol. Gas. Explor. Res. 1, 1, 014-021.

Santos S.M.G., Botechia V.E., Schiozer D.J., Gaspar A.T.F.S. (2017a) Expected value, downside risk and upside potential as decision criteria in production strategy selection for petroleum field development, J. Pet. Sci. Eng. 157, 81-93. https://doi. org/10.1016/j.petrol.2017.07.002.

Santos S.M.G., Gaspar A.T.F.S., Schiozer D.J. (2017b) Value of information in reservoir development projects: Technical indicators to prioritize uncertainties and information sources, J. Pet. Sci. Eng. 157, 1179-1197. https://doi.org/10.1016/j. petrol.2017.08.028.

Santos S.M.G., Gaspar A.T.F.S., Schiozer D.J. (2017c) Risk management in petroleum development projects: Technical and economic indicators to define a robust production strategy, J. Pet. Sci. Eng. 151, 116-127. https://doi.org/ 10.1016/j.petrol.2017.01.035.

Santos S.M.G., Gaspar A.T.F.S., Schiozer D.J. (2018a) Managing reservoir uncertainty in petroleum field development: Defining a flexible production strategy from a set of rigid candidate strategies, J. Pet. Sci. Eng. 171, 516-528. https://doi.org/10.1016/j.petrol.2018.07.048.

Santos S.M.G., Gaspar A.T.F.S., Schiozer D.J. (2018b) Comparison of risk analysis methodologies in a geostatistical context: Monte Carlo with joint proxy models and discretized latin hypercube, Int. J. Uncertain. Quan. 8, 1, 23-41. https://doi.org/10.1615/Int.J.UncertaintyQuantification. 2018019782.

Scheidt C., Zabalza-Mezghani I., Feraille M., Collombier D. (2007) Toward a reliable quantification of uncertainty on production forecasts: Adaptive experimental designs, Oil Gas Sci. Technol. - Rev. IFP Energies nouvelles 62, 2, 207-224. https://doi.org/10.2516/ogst.2007018.

Schiozer D.J., Avansi G.D., Santos A.A.S. (2017) A new methodology for risk quantification combining geostatistical realizations and discretized latin hypercube, J. Braz. Soc. Mech. Sci. 39, 2, 575-587. https://doi.org/10.1007/s40430016-0576-9.

Schiozer D.J., Ligero E.L., Suslick S.B., Costa A.P.A., Santos J. A.M. (2004) Use of representative models in the integration of risk analysis and production strategy definition, J. Pet. Sci.
Eng. 44, 1-2, 131-141. https://doi.org/10.1016/j.petrol. 2004.02.010.

Schiozer D.J., Santos A.A.S., Drumond P.S. (2015) Integrated model based decision analysis in twelve steps applied to petroleum fields development and management, in: $S P E$ EUROPEC 2015 , 1-4 June, Madrid, Spain. https://doi. org $/ 10.2118 / 174370-M S$.

Shirangi M.G., Durlofsky L.J. (2015) Closed-loop field development optimization under uncertainty, in: SPE Reservoir Simulation Symposium, 23-25 February, Houston, Texas. https://doi.org/10.2118/173219-MS.

Shirangi M.G., Durlofsky L.J. (2016) A general method to select representative models for decision making and optimization under uncertainty, Comput. Geosci. 96, 109-123. https://doi. org/10.1016/j.cageo.2016.08.002.

Silva L.O.M., Santos A.A.S., Schiozer D.J. (2016) Otimização da Estratégia de Produção sob Incertezas Geológicas e Econômicas, in: Rio Oil $\&$ Gas Expo and Conference, 24-27 October, Rio de Janeiro, Brazil.

Silva M.I.O., dos Santos A.A.S., Schiozer D.J., de Neufville R. (2017) Methodology to estimate the value of flexibility under endogenous and exogenous uncertainties, J. Pet. Sci. Eng. 151, 235-247. https://doi.org/10.1016/j.petrol.2016.12.026.

Soares R.V., Maschio C., Schiozer D.J. (2018) Applying a localization technique to Kalman Gain and assessing the influence on the variability of models in history matching, $J$. Pet. Sci. Eng. 169, 110-125. https://doi.org/10.1016/j. petrol.2018.05.059.

Subbey S., Christie M., Sambridge M. (2004) Prediction under uncertainty in reservoir modeling, J. Pet. Sci. Eng. 44, 1, 143-153. https://doi.org/10.1016/j.petrol.2004.02.011.

Touzani S., Busby D. (2014) Screening method using the derivative-based global sensitivity indices with application to reservoir simulator, Oil Gas Sci. Technol. - Rev. IFP Energies nouvelles 69, 4, 619-632. https://doi.org/10.2516/ogst/ 2013195.

Trehan S., Carlberg K.T., Durlofsky L.J. (2017) Error modeling for surrogates of dynamical systems using machine learning, Int. J. Numer. Meth. Eng. 112, 1801-1827. https://doi.org/ $10.1002 /$ nme.5583.

van Essen G., Zandvliet M., van den Hof P., Bosgra O., Jansen J.-D. (2009) Robust waterflooding optimization of multiple geological scenarios, SPE J. 14, 1, 24-27. https://doi.org/ 10.2118/102913-PA.

von Hohendorff Filho J.C., Maschio C., Schiozer D.J. (2016) Production strategy optimization based on iterative discrete latin hypercube, J. Braz. Soc. Mech. Sci. 38, 8, 2473-2480. https://doi.org/10.1007/s40430-016-0511-0.

von Hohendorff Filho J.C., Schiozer D.J. (2017) Evaluation of reservoir and production system integration in production strategy selection, in: SPE Reservoir Simulation Conference, 20-22 February, Montgomery, Texas. https://doi.org/ 10.2118/182624-MS.

von Hohendorff Filho J.C., Schiozer D.J. (2018) Effect of reservoir and production system integration on field production strategy selection, Oil Gas Sci. Technol. - Rev. IFP Energies nouvelles 73, 44. https://doi.org/10.2516/ogst/ 2018042.

Wang C., Li G., Reynolds A.C. (2009) Production optimization in closed-loop reservoir management, SPE J. 14, 3, 506-523. https://doi.org/10.2118/109805-PA.

Wilson K.C., Durlofsky L.J. (2013) Optimization of shale gas field development using direct search techniques and reduced- 
physics models, J. Petrol. Sci. Eng. 108, 304-315. https://doi. org/10.1016/j.petrol.2013.04.019.

Yang C., Card C., Nghiem L., Fedutenko E. (2011) Robust optimization of SAGD operations under geological uncertainties, in: SPE Reservoir Simulation Symposium, 21-23 February, The Woodlands, Texas. https://doi.org/10.2118/141676-MS.

Yang C., Nghiem L., Card C., Bremeier M. (2007) Reservoir model uncertainty quantification through computer-assisted history matching, in: SPE Annual Technical Conference and
Exhibition, 11-14 November, Anaheim, California. https://doi.org/10.2118/109825-MS.

Yasari E., Pishvaie M.R. (2015) Pareto-based robust optimization of water-flooding using multiple realizations, J. Pet. Sci. Eng. 132, 18-27. https://doi.org/10.1016/j.petrol.2015.04.038.

Zabalza-Mezghani I., Manceau E., Feraille M., Jourdan A. (2004) Uncertainty management: From geological scenarios to production scheme optimization, J. Petrol. Sci. Eng. 44, 1-2, 11-25. https://doi.org/10.1016/j.petrol.2004.02.002. 